\title{
Comparative study on the seismic performance assessment of existing buildings with and without retrofit strategies
}

\author{
Rakesh Dumaru ${ }^{1} \cdot$ Hugo Rodrigues ${ }^{2}$ [D $\cdot$ Humberto Varum ${ }^{3}$
}

Received: 8 May 2018 / Accepted: 7 November 2018 / Published online: 22 November 2018

(c) The Author(s) 2018

\begin{abstract}
A large number of infilled RC frame buildings have undergone moderate to extensive structural damages and even collapsed after the 2015 Gorkha earthquake. The repair and maintenance works are still being carried out in the existing RC buildings, many of them without any consultation with design engineers. Such practices are likely to create a benefit of doubt on the efficiency of the retrofitting works and repair/maintenance works. Therefore, the present study aims to evaluate the seismic performance of the existing non- and pre-engineered buildings, and later employed retrofit measures that are commonly practised in the region. The analytical results revealed that the selected buildings were seismically deficient and are most likely to undergo extensive damage to collapse states, at $0.3 \mathrm{~g}$ PGA. It was found that the retrofit measure significantly enhances the stiffness, maximum strength and ductility in the existing buildings. The pushover curves indicated that the steel bracing highly increased the stiffness, strength and ductility capacity in all case study buildings. The steel-braced building was recorded to have increased the maximum base shear capacity by almost ten times for the soft-storey MRT1 building. Similarly, the retrofit measures also eliminated the potential single storey drift concentration recorded in the original building, such that a uniform inter-storey drift profile can be attained throughout. The conditional probability of collapse for the case study buildings, at $0.3 \mathrm{~g}$ PGA, ranges from 13.5 to $42 \%$ and could be minimized below $4 \%$ in the worst case scenario for the shear wall. All the numerical results demonstrated that steel bracing was much more effective in enhancing the seismic performance of the existing buildings.
\end{abstract}

Keywords Non-engineered and pre-engineered buildings $\cdot$ Retrofit techniques $\cdot$ Irregularity of infill panels $\cdot$ IDA curves · Fragility curves

\section{Introduction}

The interaction of masonry infill panels on the frame structures has been investigated by many researches over the past four decades. The past earthquake around the globe

Hugo Rodrigues

hugo.f.rodrigues@ipleiria.pt

Rakesh Dumaru

rakesh.dumaru1@gmail.com

Humberto Varum

hvarum@fe.up.pt

1 CONSTRUCT-LESE, Faculty of Engineering (FEUP), University of Porto, Porto, Portugal

2 RISCO, ESTG- Polytechnic Institute of Leiria, Leiria, Portugal

3 CONSTRUCT-LESE, Faculty of Engineering (FEUP), University of Porto, Leiria, Portugal and its consequences on the infilled $\mathrm{RC}$ frames showed both positive and negative contributions of infill panel. The positive advantage includes increase in stiffness and strength by many folds compared to the bare frame and soft storey buildings, which reduces the inter-storey drift throughout the height (Fiorato et al. 1970; Dumaru et al. 2016; Chaulagain 2015; Asteris et al. 2011; Bertero and Brokken 1983; Furtado et al. 2015). However, this phenomenon is true for lowto medium-magnitude earthquakes, in which the demand is lower than the building capacity (Varum 2003). In addition, the experimental tests and the site survey after earthquakes revealed that the presence of infill panels even in non-ductile seismic deficient RC buildings largely reduces the probability of higher damage states (such as partial collapse and collapse) (Sattar 2013). Most of the collapsed infilled RC frame structures recorded after the Gorkha earthquakes were due to vertical irregularity of the infill wall, leading to the failure of the building under soft-storey mechanism, 
the main disadvantage of infill walls (Varum et al. 2017, 2018; Sharma et al. 2016). For large-magnitude earthquakes, the evenly distributed infill walls could also lead to various failure mechanisms, such as soft-storey, short column and shear failure in column, most likely due to brittle behaviour and various associated failure modes.

The present study classified the selected existing buildings into two design approaches based on the structural section sizes and reinforcement details. It includes nonengineered and pre-engineered buildings; the state of the building and its structural section sizes are presented in Table 1 . The non-engineered building represents building built before the introduction of any design codes, i.e. built before 1990s, and such buildings are seismically deficient and designed to carry only gravity loads. In addition, site survey after 2015 Gorkha earthquake showed that most of the pre-engineered buildings were found to have been built based on the strong-beam and weak-column design approach. In addition, such buildings possess poor concrete quality, inadequate longitudinal reinforcements and largely spaced lateral ties (poor confinement), insufficient effective cover in beam and column, short-column formation at the stair landing and irregular distribution of infill panels. Past earthquakes and experimental researches revealed that such buildings around the globe mostly failed under soft storey, due to large seismic demand concentration in a single storey under seismic actions (Varum et al. 2018; Sharma et al. 2016). The risk of collapse of non-ductile reinforced concrete (RC) frame structures is 40 times higher (in terms of annualized risk) than modern frames (Liel et al. 2010). Similarly, when non-ductile RC frames are subjected to earthquakes of 2500 return period, the conditional probability of collapse ranges from 60 to $90 \%$ (Liel 2008). Almost 6613 infilled RC buildings totally collapsed and 16,917

Table 1 General description of case study buildings

\begin{tabular}{|c|c|c|c|c|c|c|c|}
\hline \multirow[t]{2}{*}{ Building class } & \multirow[t]{2}{*}{ Damage state } & \multirow[t]{2}{*}{ Building name } & \multirow{2}{*}{$\begin{array}{l}\text { Num- } \\
\text { ber of } \\
\text { storeys }\end{array}$} & \multicolumn{2}{|l|}{ Section size } & \multirow[t]{2}{*}{ Plinth area $\left(\mathrm{m}^{2}\right)$} & \multirow[t]{2}{*}{ Remarks } \\
\hline & & & & Column $\left(\mathrm{mm}^{2}\right)$ & $\overline{\text { Beam }\left(\mathrm{mm}^{2}\right)}$ & & \\
\hline \multirow[t]{2}{*}{ Non-engineered } & Non-damaged & $\begin{array}{l}\text { Mitra Chaphakhana } \\
\text { (CCP1) }\end{array}$ & 3 & $230 \times 230$ & $230 \times 330$ & 70 & \\
\hline & Damaged & Suwal House (CCP2) & 4 & $230 \times 230$ & $230 \times 330$ & 69.60 & \\
\hline \multirow[t]{7}{*}{ Pre-engineered } & Non-damaged & Bare frame (MRT1) & 3 & $300 \times 230$ & $230 \times 355$ & 100 & \\
\hline & & & & $230 \times 230$ & & & \\
\hline & & & & $\Phi 230$ & & & \\
\hline & Damaged & $\begin{array}{l}\text { Twayana House } \\
\text { (MRT2) }\end{array}$ & 4 & $270 \times 270$ & $230 \times 330$ & 133 & \\
\hline & & & & & & & \\
\hline & & & & & & & \\
\hline & & & & & & & \\
\hline
\end{tabular}


were partially damaged due to the Gorkha earthquake: mostly non-engineered and few pre-engineered buildings (https://www.worldvision.org/disaster-relief-news-stori es/2015-nepal-earthquake-facts). Although the number of damaged/collapsed buildings was less in comparison to the total damaged buildings, the level of destructions in terms of monetary loss and human injuries and casualties were extremely high. Over time, the design philosophy and construction methods have been improved a lot in Nepal and this is visible in the existing buildings built between 2000 and 2005 before the actual implementation of design guidelines. Initially, Nepal Building Code NBC 205:1994 (1994), also commonly known as Mandatory Rule of Thumb (MRT), was implemented in 2005 and enforced as mandatory in all municipalities. However, this design guideline was utilized for drawing approval from the concerned authorities and does not match with the real construction site. Some major modifications are related to the structural section and reinforcement details and number of storeys, although the design guideline is clearly intended to be useful only for regular and three-storey buildings. The selected pre-engineered buildings do not follow all design guidelines, as it is difficult to find ideal MRT buildings due to the above-mentioned modifications in the buildings. Therefore, the present study classified two existing buildings that were built between 2000 and 2015 as pre-engineered buildings based on the recorded structural column sections and reinforcement details.

Three retrofit measures were employed that are commonly practiced in Nepal in each case study buildings and their effectiveness in enhancing the seismic performance evaluated. It includes concrete column jacketing, circular hollow section (CHS) steel bracing, and addition of RC shear wall. The primary objective of introducing retrofit measures was to minimize structural irregularities, correct discontinuities, complete the load path, uniformize inter-storey drift and obtain a regular structure for improving the seismic performance. Based on the trend of retrofit practice in Nepal, the concrete jacketing is one of the most widely practiced retrofit methods, as it does not require highly skilled manpower. It was carried out by enlarging the existing column section by adding new layer of confining concrete and reinforcing with longitudinal and transverse reinforcements. This method is particularly used for the repair and maintenance of damaged columns and beams in the building. The experimental investigations concluded that jacketing is found to be effective in improving the stiffness, lateral strength and energy dissipation capacities in the existing non-ductile structures (Goel and Lee 1990; Alcocer 1993; Altin et al. 2008; Chrysostomou et al. 2013). In addition, it also considerably enhances the shear capacity, flexural stiffness and deformation capacity of damaged or weak members (Varum 2003; Eurocode 2005; Kaplan et al. 2011). The external use of bracing retrofit has unpleasant artistic view, but it is easy to apply and does not disturb the occupants during its maintenance. Previous experimental works revealed that it effectively increases the in-plane shear strength and displacement ductility of the concrete frame (Mehrabi et al. 1996; Tasnimi and Masoomi 1999; Youssef et al. 2007). It has significant contribution to the global structural stiffness and also reduces the maximum inter-storey drift (El-Amoury and Ghobarah 2005). In addition, it also increases both stiffness and strength; however, there is a failure of the steel specimen under excessive overall buckling, followed by a secondary local buckling in the compression side, at or near the mid-length of the specimen (Gao et al. 2013). The main objective of adopting RC shear wall as retrofit measure was to increase the global lateral stiffness and strength. The experimental test results concluded a substantial increase in lateral stiffness and strength and also increases in the energy dissipation capacity of the building and, if properly located, also reduces the plan irregularities that enhance the building seismic performance (Kaplan et al. 2011; Bush et al. 1990). Taghavi and Miranda (2003) revealed that the intervention of retrofit measures reduced the damages to the non-structural components in terms of total monetary loss by approximately 62,70 and $48 \%$ of the total investment in office, hotel and hospital buildings, respectively. The present study employed the retrofit measures only in the structural elements, but the reduction of the seismic demand has a direct reduction of the non-structural drift. In addition to the increase in the seismic performance of the existing buildings, the present study also aims to reduce or minimize the potential human injuries and fatalities. The applicability and suitability of the retrofit measures in the existing buildings are mainly governed by its associated cost and benefit attained in future; thus, the study intends to introduce retrofit measures considering both enhancing seismic performance and reducing the potential cost (economic) so that maximum benefit can be obtained in future.

\section{General description of the case study buildings}

The four existing buildings were selected, representing two each for non- and pre-engineered design buildings that were recorded as damaged and undamaged during the Gorkha earthquake, as presented in Table 1. The selected buildings were grouped into the respective building classes, based on the structural column sizes and reinforcement details, as observed and measured during site survey. The entire case study buildings were located in Bhaktapur, Nepal. The non-engineered buildings were provided with a constant slab thickness of $100 \mathrm{~mm}$ and pre-engineered buildings with $125 \mathrm{~mm}$ thickness. Two types of unreinforced solid masonry infill walls were provided, such as external infill 
wall of $230 \mathrm{~mm}$ thickness mostly located in the periphery of the building and internal infill wall of $110 \mathrm{~mm}$ thickness functioning as the partition walls. In some cases, a wall thickness of $110 \mathrm{~mm}$ was found to be used as the external infill wall as well.

The CCP1 building was built in 1985 using local knowledge and skill, representing common buildings that were built before implementation of design guidelines. Figure 1a presents the CCP1 building floor and is symmetrical in plan, having four bays in the $\mathrm{N}-\mathrm{S}$ (north-south) direction and two bays in the E-W (east-west) direction. The uniform inter-storey height of $2.43 \mathrm{~m}$ is provided throughout, such that the total height of the building is $9.7 \mathrm{~m}$. Similarly, the total plinth area of the building is approximately $70 \mathrm{~m}^{2}$, where it possesses maximum bay length of $2.7 \mathrm{~m}$ along the N-S direction and $4.2 \mathrm{~m}$ along the $\mathrm{E}-\mathrm{W}$ direction. The columns are reinforced with uniform longitudinal bars of $4 \Phi 12$ and the beams are reinforced with top bars of $3 \Phi 12$ and bottom bars of $2 \Phi 12$. These are confined with transverse one-legged reinforcement bars of $\Phi 6$ and are uniformly spaced at $150 \mathrm{~mm}$ from the centre throughout the height. The CCP2 building is a four-storey ordinary RC frame building infilled with URM panels and is located in Ghalate, Bhaktapur, Nepal. The building was built in the late 1980s, which also marks the beginning of RC construction in Nepal. It is rectangular in plan with some vertical irregularity at the ground floor, such that one complete bay along the $\mathrm{E}-\mathrm{W}$ direction is without infill panels. It was constructed in two stages; the first two storeys possess uniform interstorey height of $2.75 \mathrm{~m}$ and the remaining two storeys have $2.3 \mathrm{~m}$, and thus the total height of the building is $10.3 \mathrm{~m}$. Figure $1 \mathrm{~b}$ illustrates the $\mathrm{CCP} 2$ building plan having two bays along the $\mathrm{E}-\mathrm{W}$ direction and three bays in the $\mathrm{N}-\mathrm{S}$ direction. It has a maximum bay length of $4.2 \mathrm{~m}$ and $3 \mathrm{~m}$ along the $\mathrm{N}-\mathrm{S}$ and $\mathrm{E}-\mathrm{W}$ directions, respectively. The total length is $11.16 \mathrm{~m}$ along the building's $\mathrm{N}-\mathrm{S}$ direction and $5.95 \mathrm{~m}$ along the E-W direction, such that the total plinth area is approximately $69.60 \mathrm{~m}^{2}$. The column is reinforced with longitudinal bars of $4 \Phi 12$ and reinforced in the beam; the top reinforcement is $4 \Phi 12$ and the bottom reinforcement is $3 \Phi$ 12. In addition, the lateral ties are one-legged, $\Phi 6 \mathrm{~mm}$ and uniformly spaced at $150 \mathrm{~mm}$ from the centre throughout the column and beam height.

The MRT1 is a bare frame building of three storey and was built in 2005 at the beginning of the MRT guideline implementation. It was without infill walls and was abandoned, as observed during the site survey (see Table 1). It reflects the construction practices of the locality, where initially buildings are built as a bare frame of the required storeys and after a certain time interval the infill walls are erected, beginning from the ground floor, depending upon the financial wherewithal of the owner. The MRT1 building possesses structural plan irregularity, where structural circular columns at the ground floor are replaced by rectangular columns in the first floor, and the lack of column at the beam-beam joint also increases plan irregularity. The building was also selected due to the opportunity of having a fully characterized bare frame building, where a different infill masonry scenario can be added, and vulnerability assessment for different dispositions can be investigated through static and dynamic analyses. The building possesses uniform inter-storey height of $2.74 \mathrm{~m}$, such that the total height of the building is $10.96 \mathrm{~m}$, which includes the stair cover portion at the top floor. It has four bays in the E-W direction with a maximum bay length of $4.7 \mathrm{~m}$ and two bays in the N-S direction with a maximum bay length of $3.5 \mathrm{~m}$, and the total plinth area of the building is approximately $100 \mathrm{~mm}^{2}$. The building possesses uniform beam section $(230 \times 355) \mathrm{mm}^{2}$ including a slab thickness of $125 \mathrm{~mm}$. All the columns are reinforced with longitudinal reinforcement of (4 $\Phi 16)+(2 \Phi 12)$ and with reinforced beam with top reinforcement of $3 \Phi 16$ and bottom reinforcement of $3 \Phi$ 12. Furthermore, the transverse reinforcement of 2 legged of $\Phi 7 \mathrm{~mm}$ are uniformly spaced of $150 \mathrm{~mm}$ centre throughout the beam and the column height. Finally, the MRT2 building is a five-storey building that includes one basement and was constructed in 2004, which also marked the beginning of the MRT guideline approval and implementation (NBC 205:1994 1994). Figure 1d demonstrates the MRT2 building plan having five bays along the $\mathrm{E}-\mathrm{W}$ direction with a maximum bay length of $3.58 \mathrm{~m}$ and two bays along the $\mathrm{N}-\mathrm{S}$ direction with a maximum bay length of $2.97 \mathrm{~m}$. The total height of the building is $12.58 \mathrm{~m}$ including the basement, where the building has uniform inter-storey height of $2.52 \mathrm{~m}$. The building possesses a uniform beam section of $(230 \times 330) \mathrm{mm}^{2}$ including constant slab thickness of $125 \mathrm{~mm}$. The building is reinforced with longitudinal reinforcements in the column containing $(4 \Phi 16)+(2 \Phi 12)$, and in the beam, top reinforcement of $(2 \Phi 16)+(1 \Phi 12)$ and bottom reinforcement of $2 \Phi 16$. The transverse reinforcement of $\Phi 8 \mathrm{~mm}$ is uniformly spaced at $150 \mathrm{~mm}$ from the centre throughout the beam and the column height.

The floor beam plan layout for all case study buildings is shown in Fig. 1. The plan layout for the CCP1 building is similar throughout. Similarly, the layout for the CCP2 building is also similar throughout except at the top floor plan, where it is without grid 1-2 floor area. The first floor plan for the MRT1 building is similar to the ground floor, but at the second floor the projected floor area covered by grid A-B and grid 5-6 are removed. The floor plan of the MRT2 building is similar up to the third floor, whereas the top floor only contains the floor area of grid 1-2.

In addition to the field survey, two types of in situ field tests were performed on the case study buildings: Schmidt hammer tests and ambient vibration tests. The Schmidt hammer test was performed to identify an accurate estimation of 

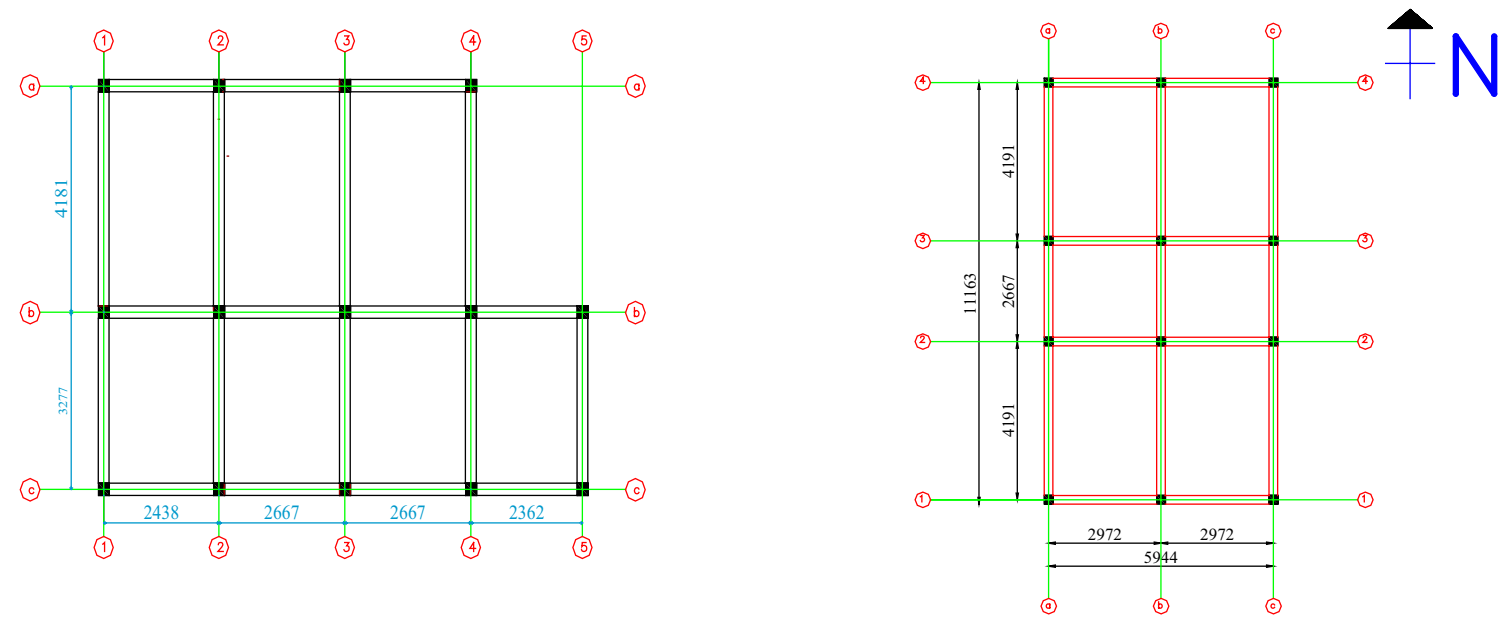

(a)

(b)

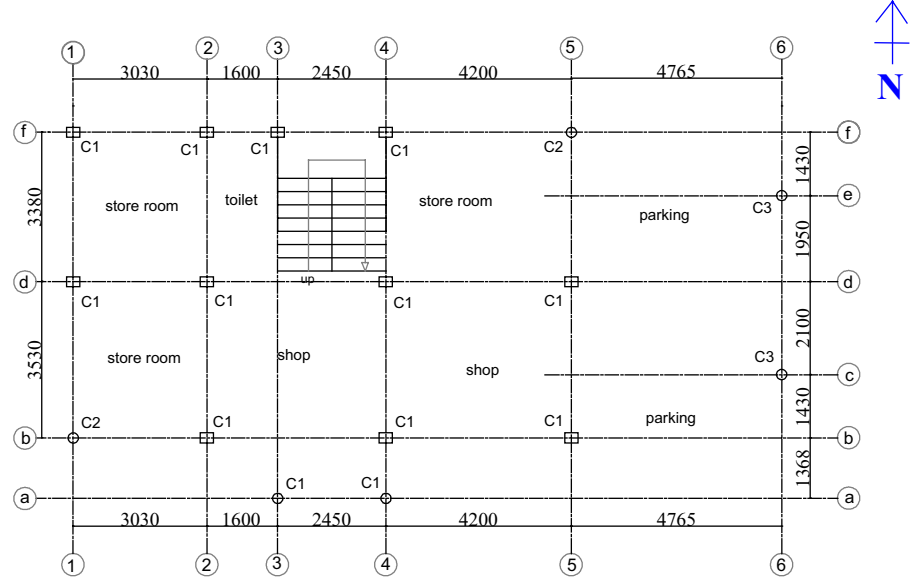

(c)

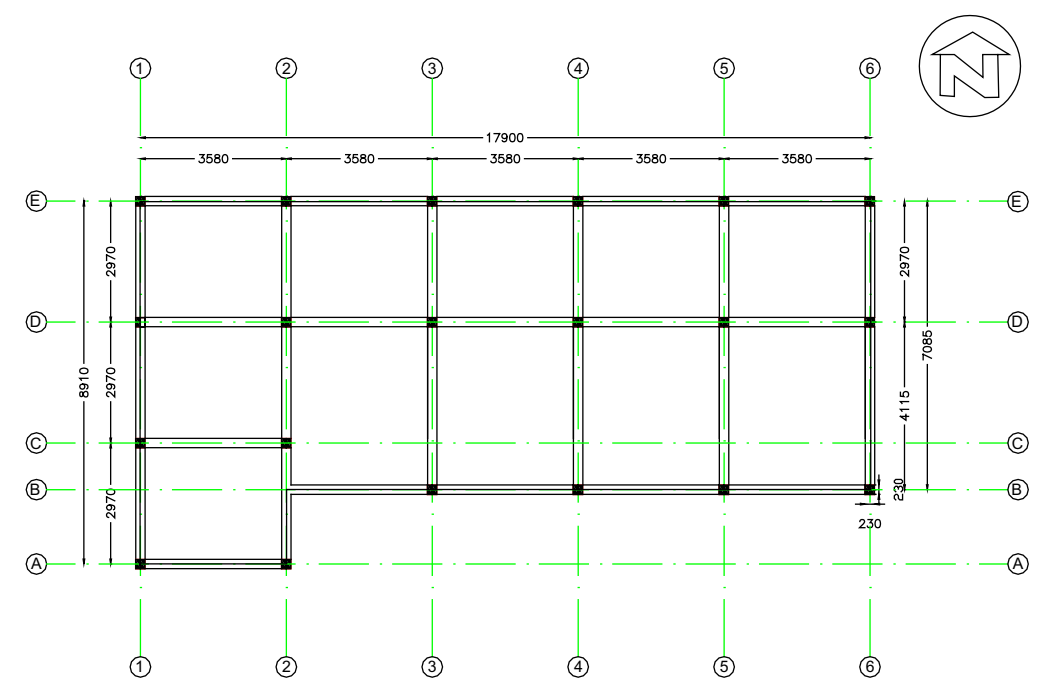

(d)

Fig. 1 Typical ground floor plan layout of each case study building; a CCP1, b CCP2, c MRT1 and d MRT2 (all dimensions are in mm) 
the existing concrete strength of the buildings, as the behaviour of the structure is highly influenced by the quality of the concrete. The recorded concrete strength was utilized for model calibration, where the comparison of global frequencies between the numerical and experimental was carried out. The experimental frequencies were measured or captured with the help of ambient vibration tests which helps to acquire the fundamental frequencies and vibration modes. The cracks observed in the model were integrated into the model through the adjustment of the modulus of elasticity of the infill panel. The detailed description of the test results and parametric study performed is out of the scope of the present study; hence, the readers are requested to look at the thesis report.

\section{Retrofit strategies and layout}

The preliminary seismic performance investigations on the existing case study buildings concluded that it revealed poor and inadequate seismic performance; thus, retrofit measures were recommended and introduced in the buildings. The present study discussed the results in detail through the comparison between the performance of the existing buildings with and without retrofit measures in terms of pushover curves, inter-storey drift profile, IDA curves and fragility curves, to justify the suitability of the selected methods. To achieve these objectives, a representative retrofit layout adopted for the CCP1 building is shown in Fig. 2. One of the initial questions considered was related with the selection of columns for jacketing. Mostly critical columns (critical in shear force and bending moments), such as corner columns and short columns were selected for jacketing. The jacketing section was designed following the procedures given by IS 15988:2013 (2013) guideline, and Sect. 8.5.1.1. For all the case study buildings, the IS 15988:2013 (2013) design code specified a minimum thickness of jacket not less than $100 \mathrm{~mm}$ in each face of the existing columns. A constant compressive strength of new jacket concrete material was assumed to be $20 \mathrm{MPa}$, such that added concrete material has compressive strength at least $5 \mathrm{MPa}$ more than in situ test results. The yield strength of the reinforcement and Young's modulus of elasticity were considered as $415 \mathrm{~N} /$ $\mathrm{mm}^{2}$ and $2 \times 10^{5} \mathrm{~N} / \mathrm{mm}^{2}$, respectively. The longitudinal bars can be efficiently anchored to the footing by applying twocomponent epoxy resin. If continuity of longitudinal bars in jacketing was needed between floors, holes were drilled in the slab to pass through. This method helps to increase column shear strength and ductility (Júlio et al. 2003). The jacketing elements were reinforced with longitudinal bars of minimum $\Phi$ 16. In addition, the lateral ties have a minimum of $\Phi 8$ and anchored at $135^{\circ}$ and uniformly spaced at 100 throughout the column height. The number of columns required to be jacketed in each floor and the number of storeys were evaluated through the attained building response, i.e. in terms of maximum inter-storey drift as an engineering demand parameter (EDP) w.r.t. IMs, as the drift was shifted from the retrofit storeys to non-retrofit storeys. Similarly, the $\mathrm{X}$-steel bracing was employed as circular hollow section (CHS) in the present study. The outer diameter and thickness of CHS for each case study building varies and was designed following the procedure specified in the standard steel code, i.e. IS 800:2007 (2007), taking into account the safety against buckling failure, which is mainly caused by axial forces and also verified if the design section is safe against given seismic loading. Its location and orientation were planned in such a way that minimize the eccentricity due to irregular distribution of infill walls and structural members, reduced or eliminated internal torsional-rotation effects, and maximized damping. Similarly, the necessity of bracing in the consecutive upper floors was evaluated through attained inter-storey drift along the height for the subjected IMs. The present study employed bracing elements in upper floors as well, due to drift shift in consecutive unbraced upper floors introduced from the lower braced floor. However, its section intends to reduce in the upper floors to meet the seismic demand, such that the building's stiffness and strength could be uniformly distributed throughout. The modulus of elasticity and yield strength of steel were considered to be $2 \times 10^{5} \mathrm{MPa}$ and $355 \mathrm{MPa}$, respectively. Furthermore, the design of shear wall begins with assumed width and thickness, such that a minimum thickness should not be less than $150 \mathrm{~mm}$, whereby various design checks were carried out with reference to IS 13920:1993 (1993). The RC shear walls were reinforced with longitudinal reinforcements in two curtains and transverse reinforcements distributed uniformly in the plane of the wall. A minimum reinforcement of $0.25 \%$ of the gross area in each direction was provided and distributed uniformly across the cross section of the wall. A constant concrete compressive strength of $20 \mathrm{MPa}$, yield strength of reinforcements of $415 \mathrm{~N} / \mathrm{mm}^{2}$ and Young's modulus of elasticity as $2 \times 10^{5} \mathrm{~N} / \mathrm{mm}^{2}$ were assumed in the study. A minimum of two shear walls in each direction was assigned to minimize eccentricities. The location and orientation of the RC shear wall depends on the existing building geometry and also the orientation of structural and non-structural elements. These elements were prioritized at large structural deficient joint or area of the building. Generally, these elements were placed between the columns, but in the present study, it was provided at the face of the column, where the centre of the column coincides with the centre of the shear wall and its width extended equally on both ends. Similarly, the number of storeys and the sections of the shear wall required to be provided were mainly governed by the respective floor inter-storey drift. Here, the shear wall was extended throughout having constant thickness, but the 


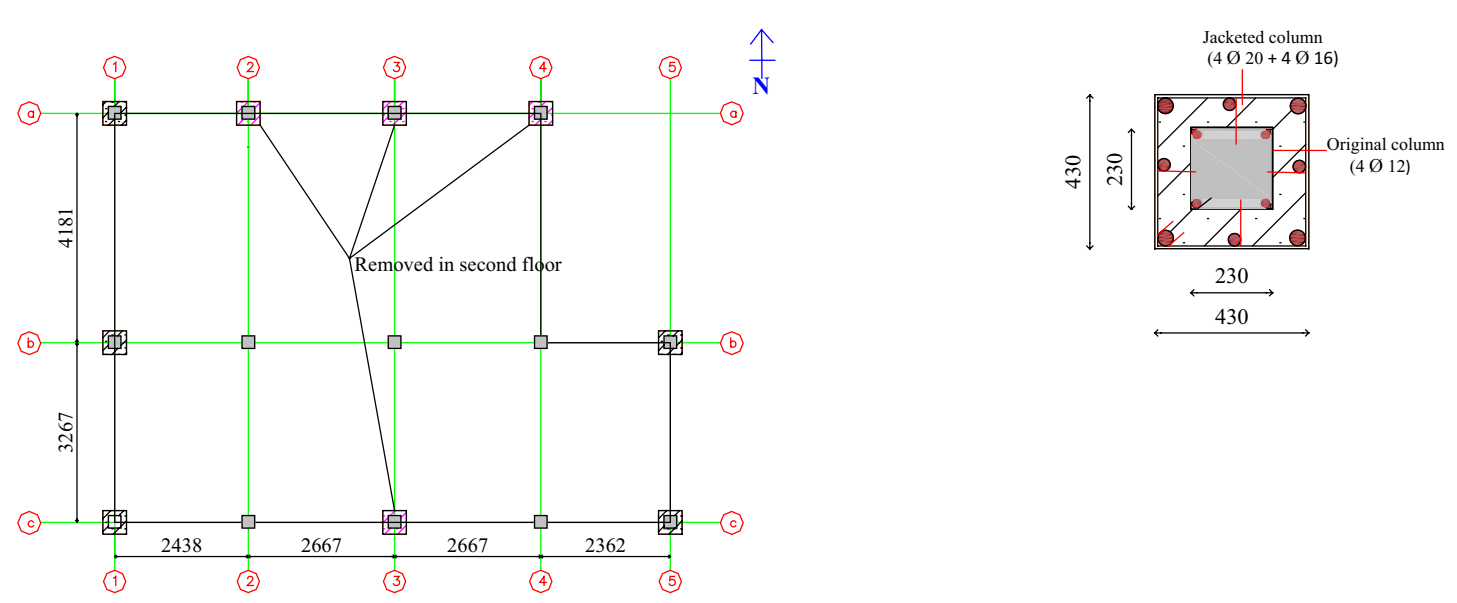

(a)



(b)
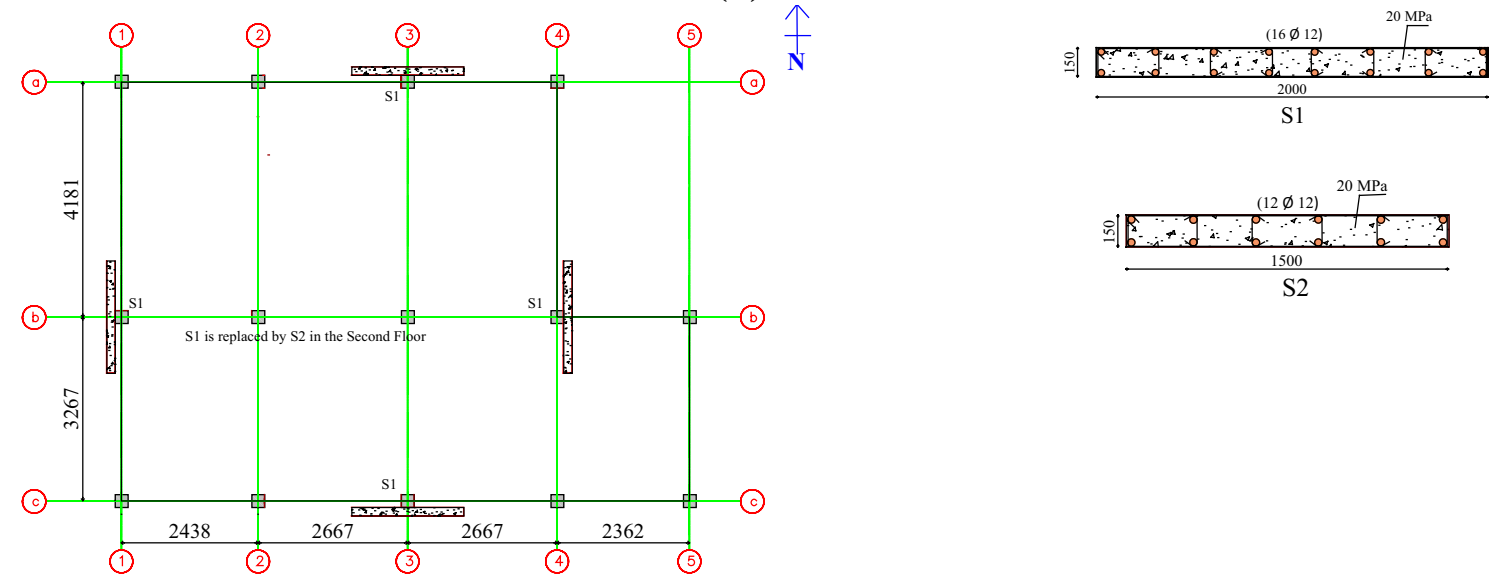

(c)

Fig. 2 Typical retrofit layout for CCP1 building; a jacketing layout and section details, b bracing layout and $\mathbf{c}$ shear wall layout and section details (all dimensions are in $\mathrm{mm}$ )

width of the shear wall was reduced along the height to meet the seismic demand and also to attain uniform drift throughout. This strategy could highly control the drift concentration in each storey, such that comparable stiffness and strength in each storey can be attained throughout.
The CCP1 building was assigned with uniform jacketed column section $(430 \times 430) \mathrm{mm}^{2}$ throughout. It was reinforced with $4 \Phi 20$ longitudinal bars at the corners and 4 $\Phi 16$ bars at the middle. The lateral ties of $\Phi 10$ uniformly spaced at $100 \mathrm{~mm}$ from the centre were assigned throughout 
the column height. A total of 9 columns out of 14 columns were jacketed at the ground and first storeys, as illustrated in Fig. 2a. It includes three columns from grid c-c, two from grid $b-b$ and four columns from grid $a-a$, represented by enlarged column sections (see Fig. 2). The first floor jacketing layout was replicated in the second floor, but jacketing columns from grid $\mathrm{c}-\mathrm{c}$ and three intermediate columns from grid a-a were removed. A typical jacketing column layout and reinforcement detail are presented in Fig. 2. As an alternative retrofit measure, the CCP1 building adopted CHS steel bracing; a typical plan layout is shown in Fig. 2b. The building is considered to have uniform CHS throughout for numerical simplicity. The assigned CHS has $130 \mathrm{~mm}$ outer diameter and $8 \mathrm{~mm}$ thickness, and the yield strength is considered as $355 \mathrm{MPa}$. Figure $2 \mathrm{~b}$ presents the bracing floor layout, where the ground and first storeys resemble similar layout, such that two bays from grid 1-1 and grid 4-4 and additional one bay from grid a-a and grid $\mathrm{c}-\mathrm{c}$ were braced, represented by dumbbell hatched surface. In addition, the first floor layout was reproduced in the second storey, but one bracing from each grid 1-1 and grid 4-4 were removed, indicated by the solid hatched surface in Fig. 2b. Furthermore, two types of shear walls were provided in the CCP1 building, i.e. "Shear wall 1" and "Shear wall 2" at the exterior periphery of the building due to availability of construction space and easier construction. Figure $2 \mathrm{c}$ presents the shear wall layout, illustrating its orientation, section size and reinforcement details. A total of four shear walls were considered in each storey, two in each direction so as to minimize the irregularities due to addition of new structural elements. It includes two types of shear walls, i.e. "Shear wall 1" and "Shear wall 2", whose section size and reinforcement detail are shown in Fig. 2c. Both shear walls were reinforced in two layers with $\Phi 12$ longitudinal bars and uniformly spaced, such that Shear wall 1 and Shear wall 2 comprised 16 and 12 longitudinal bars, respectively. Furthermore, it was reinforced with transverse reinforcements of $\Phi 12$, uniformly spaced at $200 \mathrm{~mm}$ from centre throughout. The ground and first storeys of the CCP1 building were considered to have four shear walls of the same section, i.e. Shear wall 1 . The first storey layout was extended into the second storey, but Shear wall 1 was replaced with Shear wall 2.

For other case study buildings, the retrofit layout is not shown in the present paper, but the section sizes and reinforcement details adopted are summarized in Table 2. Two types of concrete column jacketing were employed for the CCP2 building: J1 and J2. A total of 7 columns were jacketed out of 12 columns at the ground floor and continued in the first and second floors (includes entire columns of grid a-a and grid $\mathrm{d}-\mathrm{d}$, and central column of grid $\mathrm{b}-\mathrm{b}$ and central column of grid b-b). More columns were jacketed on the southern face of the building to counterbalance the eccentricity developed by the irregular distribution of infill walls and also to compensate the damage observed in the corner columns of grid a-a, mainly at the ground floor. Similarly, in the top floor the central column of grid $\mathrm{b}-\mathrm{b}$ and the entire columns of grid $\mathrm{d}-\mathrm{d}$ were jacketed. The steel bracing for the CCP2 building had a uniform section of outer diameter $100 \mathrm{~mm}$ and $5 \mathrm{~mm}$ thickness. Two steel bracings along the longer direction and four bracings along the building shorter direction were provided, starting from the ground to second floors. In the top floor, two bracings in each direction were provided. The building was assigned with two types of shear wall: one barbell type and the other simple type. At the ground floor, the longer direction of the building was provided with two barbell-type shear wall, and the shorter direction with three shear walls (i.e. two barbell
Table 2 Summary of the detailing retrofit methods assigned for the case study buildings

\begin{tabular}{|c|c|c|c|c|c|c|c|}
\hline \multirow[t]{4}{*}{ Bldg. name } & \multicolumn{7}{|c|}{ Retrofit methods } \\
\hline & \multicolumn{2}{|l|}{ Jacketing } & \multicolumn{2}{|c|}{ Bracing } & \multicolumn{3}{|c|}{ Shear wall } \\
\hline & \multirow[t]{2}{*}{ Section $\left(\mathrm{mm}^{2}\right)$} & \multirow{2}{*}{$\begin{array}{l}\text { Total long. } \\
\text { reinforcement } \\
\left(\mathrm{mm}^{2}\right)\end{array}$} & \multirow{2}{*}{$\begin{array}{l}\text { Outer } \\
\text { dia. } \\
(\mathrm{mm})\end{array}$} & \multirow[t]{2}{*}{$t(\mathrm{~mm})$} & \multicolumn{2}{|c|}{ Section $\left(\mathrm{mm}^{2}\right)$} & \multirow{2}{*}{$\begin{array}{l}\text { Total long. } \\
\text { Reinforcement } \\
\left(\mathrm{mm}^{2}\right)\end{array}$} \\
\hline & & & & & $t(\mathrm{~mm})$ & $b(\mathrm{~mm})$ & \\
\hline \multirow[t]{2}{*}{ CCP1 } & $430 \times 430$ & $4 \Phi 20+4 \Phi 16$ & 130 & 8 & 150 & 2000 & $16 \Phi 12$ \\
\hline & & & & & & 1500 & $12 \Phi 12$ \\
\hline \multirow[t]{2}{*}{$\mathrm{CCP} 2$} & $430 \times 430$ & $8 \Phi 20$ & 100 & 5 & 230 & 2000 & $24 \Phi 12$ \\
\hline & $430 \times 530$ & $8 \Phi 20$ & & & 230 & 1250 & $12 \Phi 12$ \\
\hline \multirow[t]{4}{*}{ MRT1 } & $480 \times 530$ & $8 \Phi 20$ & 130 & 8 & 230 & 2000 & $20 \Phi 12$ \\
\hline & & & 120 & 8 & & & \\
\hline & $530 \times 530$ & $8 \Phi 20$ & 100 & 7 & 230 & 1200 & $12 \Phi 12$ \\
\hline & & & 70 & 5 & & & \\
\hline \multirow[t]{3}{*}{ MRT2 } & $500 \times 500$ & $8 \Phi 20$ & 100 & 5 & 250 & 2500 & $24 \Phi 12$ \\
\hline & & & 140 & 7 & 250 & 1800 & $18 \Phi 12$ \\
\hline & & & & & 250 & 1400 & $14 \Phi 12$ \\
\hline
\end{tabular}


type and one simple type). Identical ground shear wall plan was extended up to the top floor plan, but simple shear wall type was removed after the ground floor. The extra shear wall at the ground floor was assigned to balance deficiency and eccentricity produced by the irregular distribution of the infill walls, where complete bay of grid a-a was without infill walls and the corner columns were also observed to be damaged.

The MRT1 building was employed with three types of jacketing: J1, J2 and J3. A total of 9 columns were jacketed out of 17 columns at the ground floor, which includes 2 end columns from grid 5-5, 3 columns from grid 4-4, 1 column from grid 3-3, 2 end columns from grid 1-1 and a central column from grid 2-2. The ground floor jacketing layout was replicated in the first and second storeys, but a column from grid 4-4-B-B (i.e. B-5) was removed. Similarly, the MRT1 building was employed with four types of CHS: B1, B2, B3 and B4. The bracing layout was similar throughout, where the entire bays of grid 1-1 and grid 5-5, and the end bays of grid B-B and grid F-F were braced. The ground floor was assigned with steel bracing B1 and B2 along the $\mathrm{N}-\mathrm{S}$ and E-W directions, respectively. Similarly, the first floor was braced with bracing element B3, and in the second floor it was replaced with bracing element B4. Finally, the MRT1 building was assigned with two types of shear wall: S1 and S2. The ground floor was provided with four shear walls (i.e. S1): two in each opposite direction. The shear wall of same section was assigned to minimize potential irregularities due to new added structural elements (shear wall) and also to neutralize or minimize the eccentricities in the existing building. This includes two shear walls constructed at the external face and remaining two shear walls internally. The shear wall configuration was extended throughout the building with modified section at the upper storeys. The MRT2 building was provided with a uniform section of jacketing throughout. A total of 13 columns out of 20 columns were jacketed at the basement, including entire columns of grid 1-1 and 6-6, 3 columns from grid 2-2, 1 central column from grid 3-3 and 2 end columns of grid 4-4. The basement layout was reproduced to the ground floor, where one of the columns from grid 2-2-C-C was not jacketed. Similarly, the jacketing layout was replicated in the first floor, where one central column from grid 3-3 was removed. Furthermore, the first floor jacketing layout was repeated at the second floor, where jacketed column from grid 3-3-D-D was removed. Finally, the top floor was jacketed which consists of two columns from grid 1-1 and grid 2-2. Two types of bracing were considered, i.e. B1 and B2. The steel bracing, $\mathrm{B} 1$ was assigned along the building's $\mathrm{N}-\mathrm{S}$ direction and $\mathrm{B} 2$ along the $\mathrm{E}-\mathrm{W}$ direction. The bracing layout was identical to the basement and ground storeys, which includes all bays from grid 1-1, mid-bay from grid 2-2, one bay from grid 6-6, two bays from grid E-E and also each bay from grid
$\mathrm{A}-\mathrm{A}$ and grid $\mathrm{B}-\mathrm{B}$. The bracing layouts for the first and second floors were also identical to that of the ground floor, but bracing from the end bays of grid 1-1 was removed. The building was provided with three types of shear wall: S1, S2 and S3. Three shear walls were provided (two external and one internal) along the $\mathrm{N}-\mathrm{S}$ direction and two along the $\mathrm{E}-\mathrm{W}$ direction of the same section, i.e. S1 at the basement and ground floors. Similar shear wall layout was extended up to the second floors, but S1 was replaced with S2 along the $\mathrm{E}-\mathrm{W}$ direction. Furthermore, the top floor was provided with two shear walls only in the N-S direction.

\section{Modelling approach}

The case study buildings with and without retrofit measures were modelled using SeismoStruct software (Seismosoft 2004), which is based on the fibre-based finite element analysis. The accuracy of the software was evaluated through the comparison between experimental and numerical results. The software contains verification reports for large sets of models and its validation with the experimental results under linear and non-linear analyses (Seismosoft 2004). Similarly, Smyrou et al. (2011) and Rodrigues (2012) also performed a large set of numerical analyses and concluded that the SeismoStruct results hold a good agreement with the experimental results. In addition, (Delgado et al. 2005; Savoia et al. 2010; Shokrzadeh and Miri 2012; Barkhordari et al. 2013; Furtado et al. 2014) carried out tests for different strengthening techniques, validated numerically using different commercial softwares and revealed that the SeismoStruct software results were in quite reasonable agreement.

All the beams, columns, jacketing elements, bracing elements and shear walls were modelled as inelastic forcebased frame element type. These elements were modelled by connecting two end nodes and were discretized into five integration sections to accurately model the softening range. Each cross section was again divided into 150 section fibres except in the case of shear wall, which was divided into 200 fibres. Each fibre is associated with uniaxial stress-strain relationship and the sectional behaviour of the beam-column elements were obtained through the integration of the nonlinear stress-strain response of the individual fibres. At the element level, all the frame elements were modelled as lumped plasticity model except the shear wall, which was modelled as distributed plasticity as bending governs the structural behaviour and such type of elements were expected to exhibit significant shear cracks at the mid-height. The concrete nonlinear model is based on the consecutive relationship proposed by Mander et al. (1988), which emphasized the transition of the stress-strain relation upon the crack opening and closure. The uniaxial non-linear constant confinement model was considered as proposed by 
Martinez-Rueda and Elnashai (1997), initially programmed by Madas and Elnashai (1992). The lateral transverse reinforcement confinement effect is incorporated by Mander et al. (1993), whereby constant confining pressure is assumed throughout the entire stress-strain range. The steel material is modelled as uniaxial bilinear stress-strain model with kinematic strain hardening, as proposed by Menegotto and Pinto (1973) and is coupled with isotropic hardening rules proposed by Filippou and Fenves (2004). Bauschinger effect (Bauschinger 1887) is considered in the model to represent steel degradation and consequently both the concrete and steel (i.e. column stiffness) degradation under cyclic loading. Under uniaxial compression, the concrete strain corresponding to the point of unconfined peak stress was assumed to be 0.002 . For concrete model, the tensile stress capacity was assumed to be 0 . The Poisson's ratio $\left(\nu_{\mathrm{c}}\right)$ for concrete under uniaxial compressive stress was considered to be 0.2 . The modulus of elasticity of concrete $\left(E_{\mathrm{c}}\right)$ is calculated using the empirical formula given by IS 456: 2000 (IS 2000), $E_{\mathrm{c}}=5000 \sqrt{ } f_{\mathrm{ck}}$, where $f_{\mathrm{ck}}$ is the concrete compressive strength of 28 days. The specific weight of the concrete material $\left(\gamma_{\mathrm{c}}\right)$ is considered as $24 \mathrm{kN} / \mathrm{m}^{3}$.

Furthermore, the macro-model approach was used to model infill panels and assigned as inelastic infill panel element as proposed by Crisafulli (1997), which considered six struts. The two pairs of strut function as compression-tension diagonal struts that transfer the axial loads between the diagonal corners. A pair of shear struts with shear spring to carry the shear from top to the bottom of the infill walls, as illustrated in Fig. 3. It consists of four internal nodes to account for the width and height of the columns and beams, respectively, whereas four dummy nodes were employed to account for the contact length between the frame and the infill panel (Seismosoft 2004). No special intermediate bonding at the interface between the infill walls and frame elements was provided. Therefore, the forces (i.e. moment and shear forces, etc.) from infill walls were transferred only at the connecting end nodes of the column. All the masonry modes of failure are difficult to capture due to large uncertainties and complexity involved; thus, the present strut model considered a shear failure of the infill wall as utilized by Smyrou et al. (2011). The diagonal strut member has the same thickness as that of masonry, but without considering the plaster thickness and its length equal to the diagonal length between the compression corners of the frame. The effective width of the diagonal strut was estimated using the relation proposed by Holmes (1961). The cross-sectional area was obtained as the product of effective width and thickness of the strut. The opening in the infill walls was integrated in the model by reducing the value of the strut area that ranged between 30 and $40 \%$, which is comparable to the one proposed by Pinho and Elnashai (2000).

A representative building model for the CCP1 building with various retrofit measures modelled in SeismoStruct software (Seismosoft 2004) is presented in Fig. 4.

Fig. 3 Six struts model for the infill panel proposed by Crisafulli 1997



Compression/Tension Struts

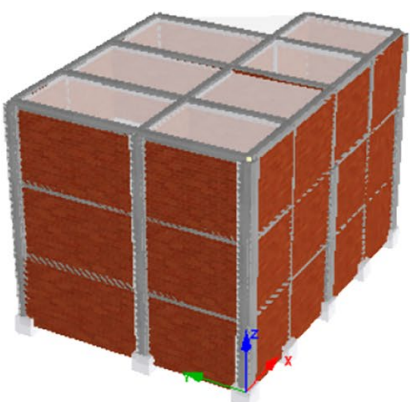

(a)

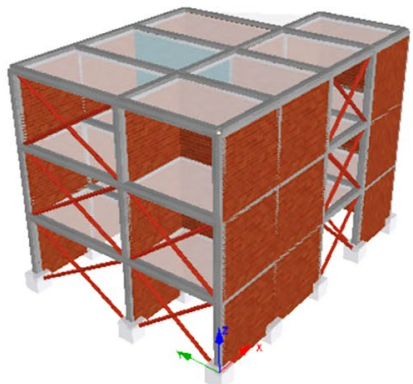

(b)

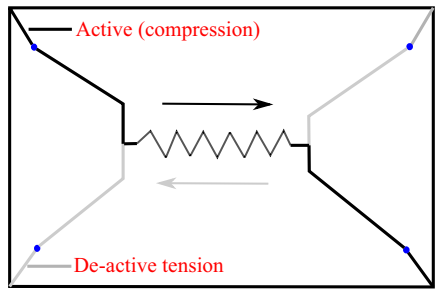

Shear Strut



(c)

Fig. 4 Representative retrofit measure model for the CCP1 model in SeismoStruct software; a jacketing, b bracing and $\mathbf{c}$ shear wall, respectively 


\section{Ground motion records selection procedure}

The seismic vulnerability assessment of each case study building was performed using the incremental dynamic analysis (IDA) method. For this, a total of 21 recorded real ground motion earthquakes were selected from the real seismic events according to Macedo et al. (2013) that matches with the target response spectra of the site. The present study selected the response spectrum for the Kathmandu Valley, similar to that defined in IS 1893(Part 1): 2002 (IS 1893), for the zone $V$ and medium type of soil, as demonstrated in Fig. 5a. Ram and Wang (2013) estimated the PGA values in the bedrocks of Nepal using a probabilistic approach. According to Ram and Wang (2013), the annual probability of exceedance of PGA values for a range of $0.07-0.16 \mathrm{~g}$ is $63 \%$, PGA between 0.21 and $0.62 \mathrm{~g}$ is $10 \%$, and between 0.38 and $1.1 \mathrm{~g}$ is $2 \%$, for earthquakes of return period 50 years. Similarly, Shrestha (2014) predicted the PGA values for the Kathmandu Valley. The study revealed that there is $2 \%$ annual probability of exceeding, $0.31 \mathrm{~g} \mathrm{PGA}$, in 50 years that is equivalent to Modified Mercalli Intensity (MMI) of VIII. Furthermore, there is $10 \%$ annual probability of exceeding a PGA of $0.18 \mathrm{~g}$ having earthquakes of 50 years return period, i.e. similar to MMI of VII. An earthquake of MMI IX that is comparable to the 1934 Nepal-Bihar earthquake of PGA between 0.5 and $0.55 \mathrm{~g}$ has $0.7 \%$ annual probability of exceedance in 50 years (Shrestha 2014). Subedi and Parajuli (2016) established that the earthquakes of 475 year return period can have maximum PGA of $0.3 \mathrm{~g}$ for hard soil, $0.4 \mathrm{~g}$ for medium soil and $0.5 \mathrm{~g}$ for soft soil.
The NBC 000:1994 1994 defined an earthquake of return period 50 years for the ordinary importance residential buildings, whereas for the strengthened buildings the return period was selected as 300 years. Therefore, a return period between 50 years and 300 years could be used for defining the damage and safety limit, respectively. Considering previous researches' prediction in the context of Nepal, the selected earthquakes have PGA ranges between 0.08 and $0.921 \mathrm{~g}$. The selected ground motion records also matches the target spectrum having range of periods between 0.1 and $1.1 \mathrm{~s}$ that covers the fundamental periods of the entire case study buildings (Ricci et al. 2016). The selected ground motion records have magnitude higher than 5.5 and an epicentre distance larger than $10 \mathrm{~km}$. All the real ground motion records considered in the study meet the target spectra (see Fig. 5b). In addition, the selection of ground motion records also ensures that for this period, and the spectral values of individual natural records are within a bound defined by $\pm 50 \%$ of the target spectral values. The selected ground motion records were scaled at the interval of $0.1 \mathrm{~g}$ and scaled up to $0.5 \mathrm{~g}$. The maximum response under two components is usually more than one component in linear and nonlinear behaviour (Khoshnoudian and Poursha 2004; Lopez et al. 2000). Therefore, the seismic excitation was subjected as a bi-directional component of the earthquakes applied at the support of the structures under arbitrary angle. Similarly, the components of record were rotated by $90^{\circ}$, such that the critical damage assessment can be identified for the structure. The arbitrary angle of seismic excitation can be varied from $0^{\circ}$ to $180^{\circ}$ at an interval of 1 degree to find the critical angle of incidence.

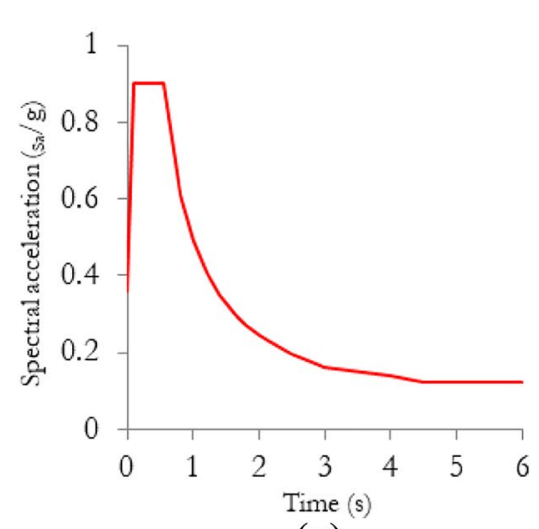

(a)

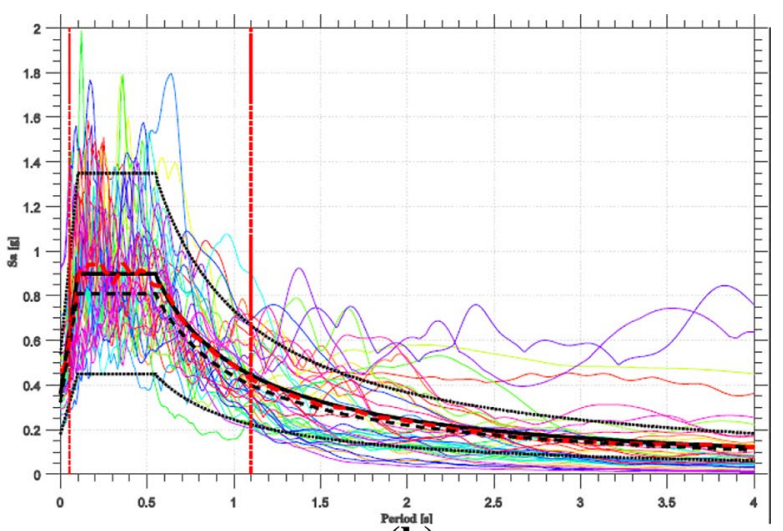

(b)

Fig. 5 a Expected response spectra for zone V and medium soil as per IS 1893 and b elastic spectrum of real ground motion selected according to Macedo et al. (2013) 


\section{Defined threshold limit states}

Limit state is related with the state of a structure beyond which it no longer fulfils the defined design criteria. In other words, it is a measure to describe the state of the structure based on a predefined level of damage, such as cracking, yielding and collapse. Several researchers and various international guidelines proposed the threshold drift limits for the different types of buildings to define the performance limit states for RC building, such as FEMA-273 1997 (FEMA273 1997), SEAOCO-VISION (2000) (SEAOC 1995), Rossetto and Elnashai 2003), Ghobarah (2004), etc. The various performance levels associated with the overall building response in terms of inter-storey drift limits for the frame without infills (i.e. bare frame) was proposed by FEMA-273 (FEMA-273 1997) and SEAOCO-VISION (2000) (SEAOC 1995). In addition, the threshold drift proposed by Ghobarah (2004) was observed to be more conventional and conservative, as the infilled buildings were expected to collapse for a drift above $1 \%$, which does not seem practicable and is not a usual scenario with recorded previous earthquake damages and collapse of the infilled buildings around the globe. Therefore, the present study aims to evaluate the state of the building through the comparison of the threshold as proposed by Rossetto and Elnashai (2003), as presented in Table 3. The illustrated drift limits are applicable for large building cases, such as non-ductile MRF, infilled MRF and shear walls. The present study considered four different building cases (one bare frame and other infilled); thus for consistent comparison, the inter-storey drift associated with all the categories was considered.

\section{Results and discussions}

\section{Adapative pushover analysis}

The increase in horizontal capacity of the existing buildings after intervention of retrofit measures was investigated using static pushover analysis. The pushover analysis was carried out for the MRT1 building using the conventional (uniform and triangular) and the adaptive (based on the response spectrum of the building) approaches to evaluate the capacity of the as-built and retrofitted buildings (Dumaru et al. 2016). However, it was observed that the adaptive pushover provides an intermediate capacity and provides closest results obtained with non-linear dynamic time history analyses (Antoniou and Pinho 2004); thus, the study presented capacity curves based on this approach. Figure 6 presents the capacity curves for all the selected buildings with and without retrofit measures. The plot demonstrates a significant increase in stiffness, strength, and ductility capacities in the existing building after introducing retrofit measures. The indices used in the plots represent building retrofitted with jacketing $(J)$, bracing $(B)$ and shear wall $(S)$, respectively, and $X$ and $Y$ are the building $X$ and $Y$ directions, respectively. The entire capacity curves illustrated that the steel bracing attained the maximum gain in stiffness and base shear capacity, followed by shear wall and jacketing, respectively. Figure 6a shows the capacity curve for the CCP1 building in both directions, and the retrofit measure increases the initial stiffness by four to seven times and maximum base shear capacity by two to three times in both directions relatively compared to the as-built CCP1 building. The capacity curve for the CCP2 building is shown in Fig. 6b, illustrating the increase in stiffness ranges from 1.5 to 2.5 times in both directions and increase in maximum base shear capacity ranges from 2.2 to 3.7 times along the $X$ direction and 1.7-2.5 times in the $Y$ direction as compared to the existing CCP2 building. The capacity curve for the MRT1 building

Table 3 Inter-storey drift limit proposed by Rossetto and Elnashai (2003)

\begin{tabular}{|c|c|c|c|c|c|}
\hline Damage state & All & Non-ductile MRF & Infilled MRF & Shear walls & Expected damage in structural and non-structural elements \\
\hline None & 0 & 0 & 0 & 0 & No damage \\
\hline Slight & 0.13 & 0.32 & 0.05 & 0.26 & Fine cracks in plaster partitions/infills \\
\hline Light & 0.19 & 0.43 & 0.08 & 0.34 & $\begin{array}{l}\text { Cracks initiates at wall-frame interfaces, diagonal cracking of walls, } \\
\text { limited crushing of bricks at beam-column connections }\end{array}$ \\
\hline Moderate & 0.56 & 1.02 & 0.30 & 0.72 & $\begin{array}{l}\text { Increased brick crushing at beam-column interfaces, some diagonal } \\
\text { shear cracking in members especially for exterior frames }\end{array}$ \\
\hline Extensive & 1.63 & 2.41 & 1.15 & 1.54 & $\begin{array}{l}\text { Partial failure of many infills, heavier damage in frame members, some } \\
\text { failure in shear }\end{array}$ \\
\hline Part. collapse & 3.34 & 4.27 & 2.80 & 2.56 & $\begin{array}{l}\text { Beams and/or column failure in shear causing partial collapse, near total } \\
\text { infill failure }\end{array}$ \\
\hline Collapse & $>4.78$ & $>5.68$ & $>4.36$ & $>3.31$ & Complete or impending building collapse \\
\hline
\end{tabular}




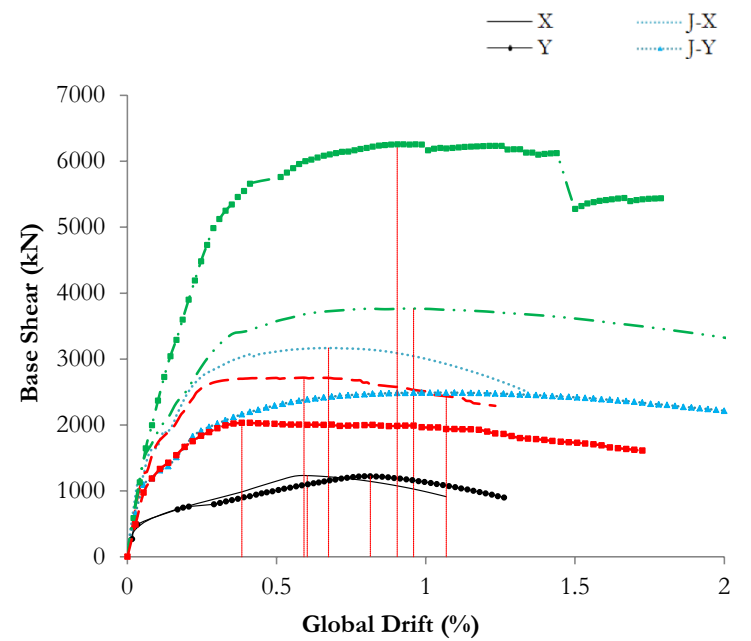

(a)

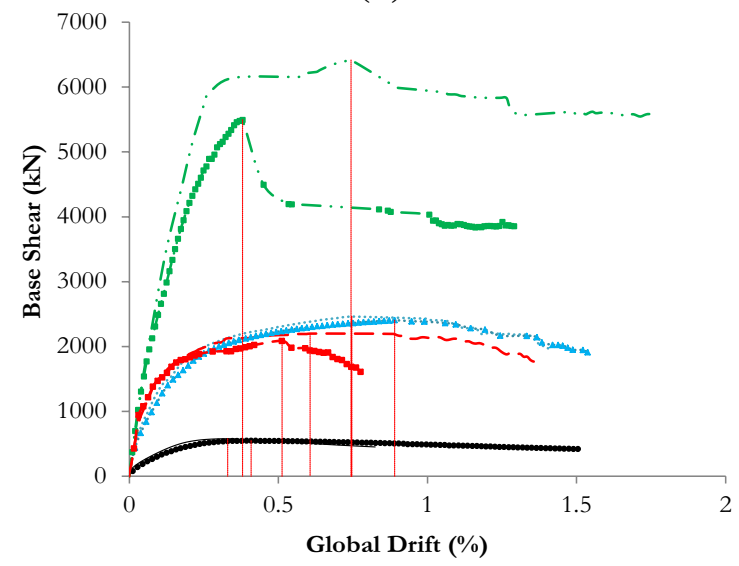

(c)

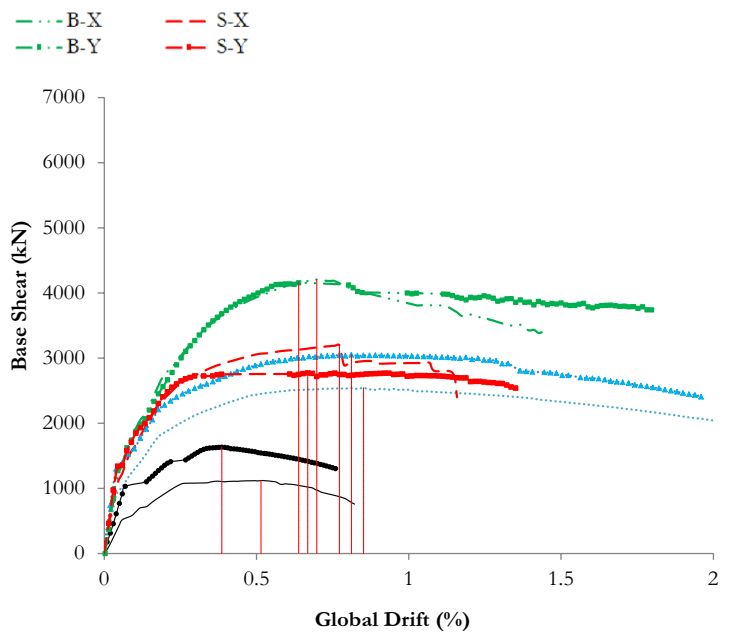

(b)

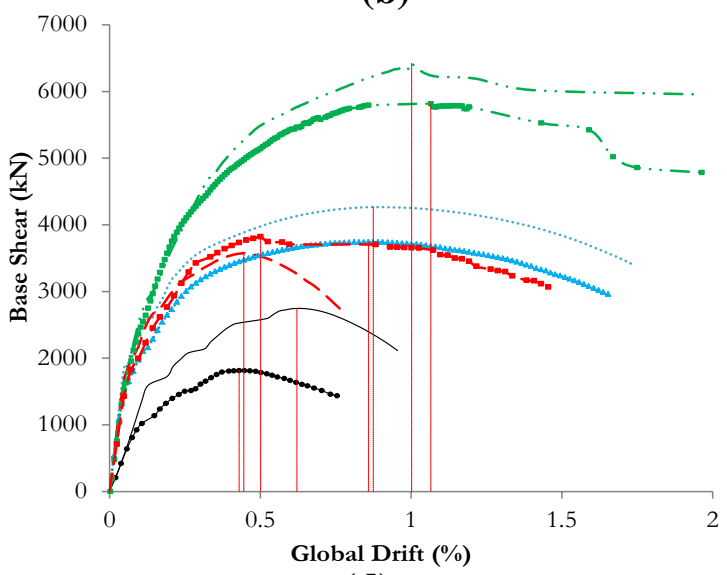

(d)

Fig. 6 Comparative capacity curve between the existing building and its retrofit; a CCP1, b CCP2, c MRT1 and d MRT2. J Jacketing, $B$ bracing and $S$ shear wall

is illustrated in Fig. 6c, where the increase in initial stiffness was almost 3.5-7 times and maximum base shear capacity by $4-10$ times. Figure $6 \mathrm{~d}$ presents the capacity curve for the MRT2 building and shows that the shear wall exhibits lower ductility. Furthermore, the increase in stiffness was 1.5-3 times in both directions and increase in maximum strength ranged from 1.3 to 2.3 times in the $X$ direction and 1.5-3 times in the $Y$ direction relatively compared to the existing MRT2 building.

\section{Non-linear dynamic time history analysis}

The non-linear dynamic time history analysis is the best method for the identification of building response under seismic excitations; however, the accuracy of the result depends upon the number and selection of ground motion records. As discussed in Sect. "Ground motion records selection procedure", the study demonstrated results acquired through the non-linear time history analyses performed through the selected real ground motion records and suitably scaled IMs. These records were subjected to be bidirectional at the support along $0^{\circ}$ and $90^{\circ}$. Therefore, a total of 10 intensity measures (IMs) were generated for each record and a total of 840 (i.e., $210 \times 4$ ) IMs were applied in each case study building (includes the as-built and retrofit measures). The seismic performance of the building was evaluated with the help of building response as the maximum inter-storey drift and the level of damages was evaluated through the comparison between the seismic demand obtained from the nonlinear dynamic time history analysis and building capacity in terms of threshold drift proposed by Rossetto and Elnhashai (2003), as illustrated in Table 3.

\section{Maximum inter-storey drift $\left(\mathrm{ISD}_{\max }\right)$ profile}

The seismic performance of the existing building after introducing the retrofit measures was evaluated through the comparison of the inter-storey drift profile. Figures 7, 8, 9, 
Fig. 7 Representative comparative $\mathrm{ISD}_{\max }$ for the CCP1 building with retrofit methods due to the 11-ChiChi Taiwan earthquake at $0.3 \mathrm{~g}$ PGA along the $X$ and $Y$ directions, respectively. $J$ Jacketing, $B$ bracing and $S$ shear wall
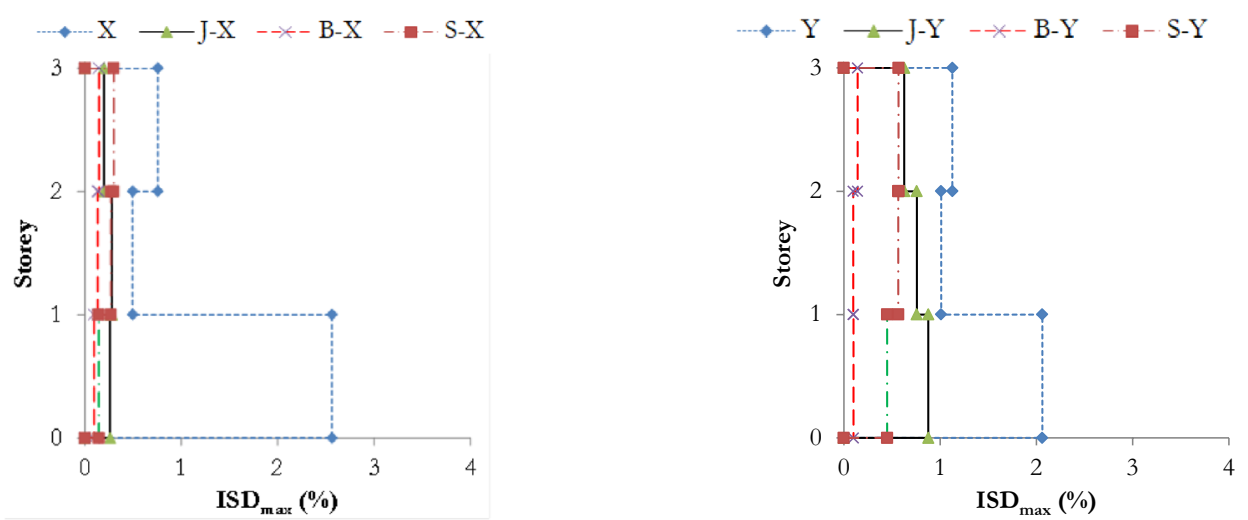

Fig. 8 Representative comparative $\mathrm{ISD}_{\max }$ for the $\mathrm{CCP} 2$ building with retrofit methods due to the 11-ChiChi Taiwan earthquake at $0.3 \mathrm{~g}$ PGA in the $X$ and $Y$ directions, respectively. $J$ Jacketing, $B$ bracing and $S$ shear wall
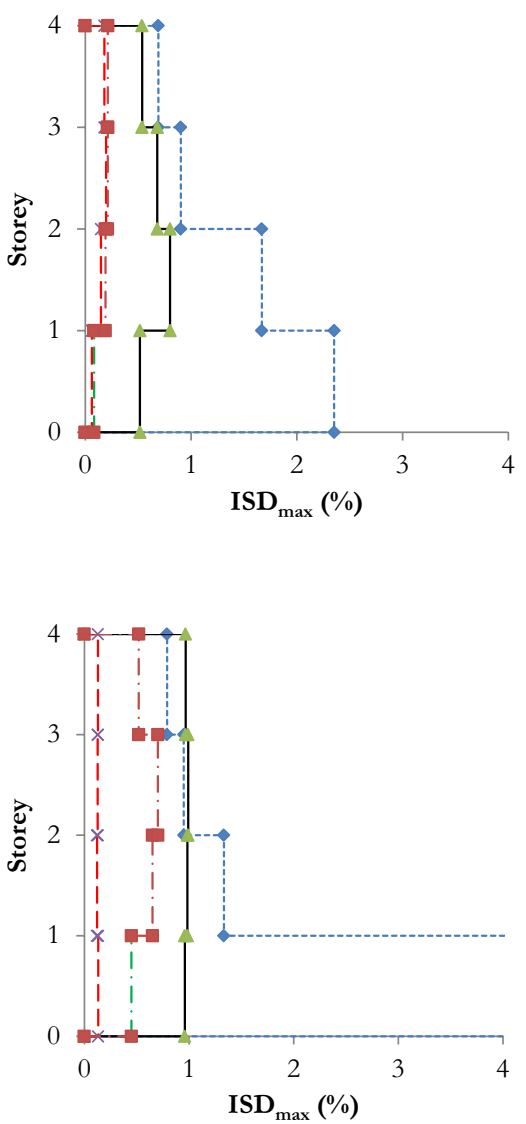
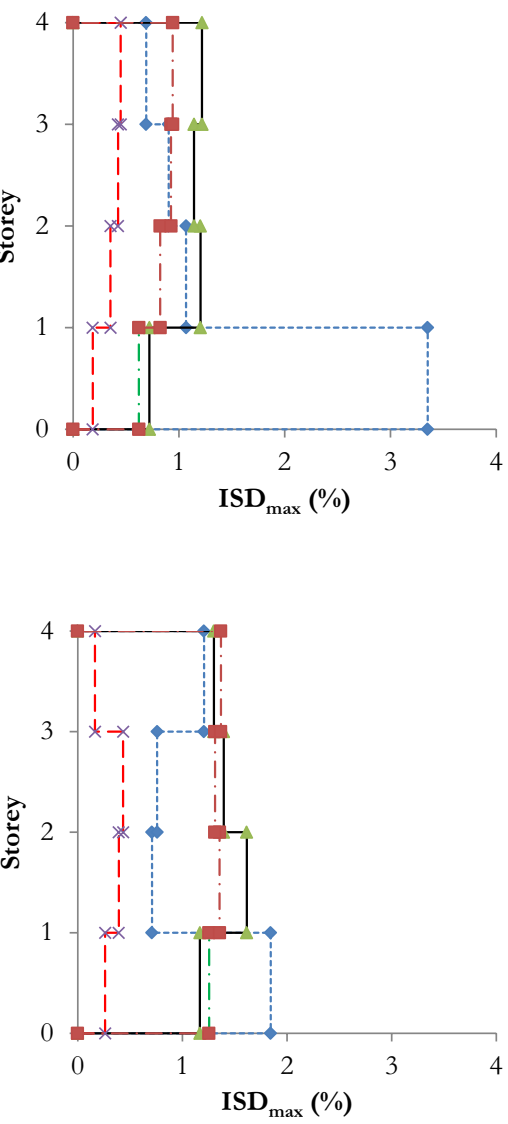

Fig. 9 Representative comparative ISD $_{\max }$ for the MRT1 building with retrofit methods due to the 11-ChiChi Taiwan earthquake at $0.3 \mathrm{~g}$ PGA in the $X$ and $Y$ directions, respectively. $J$ Jacketing, $B$ bracing and $S$ shear wall
10 presents the distribution of inter-storey drift for construction with and without retrofit measures in the existing buildings, subjected to the 11-ChiChiTaiwan earthquake, at $0.3 \mathrm{~g}$ PGA. All of the plots illustrated that the inter-storey drift was reduced significantly with the addition of retrofit strategies. In addition, the ISD $_{\text {max }}$ concentration in a single storey mostly at the ground storey in the original building was significantly reduced, where uniform distribution of drift in both directions was attained. This indicates that uniform distribution of stiffness and strength was attained through the retrofit additions, a primary objective of the present study.
It was also observed that the steel bracing was found to be more effective in reducing drift to a larger extent, followed by shear wall and jacketing, respectively. The inter-storey drift profile for the CCP1 building with and without retrofit is shown in Fig. 7, and revealed that the $\mathrm{ISD}_{\max }$ was reduced by almost five to ten times in the $X$ direction and two to four times in the $Y$ direction compared to the original CCP1 building. The ISD ${ }_{\text {max }}$ profile for the CCP2 building is presented in Fig. 8 and it was found that steel bracing highly reduced the $\mathrm{ISD}_{\max }$ to lower values, i.e. $<0.5 \%$ in both directions. In addition, the retrofit measure could reduce the 
Fig. 10 Representative comparative $\mathrm{ISD}_{\max }$ for the MRT2 building with retrofit methods due to 11-ChiChi Taiwan earthquake at $0.3 \mathrm{~g}$ PGA in the $X$ and $Y$ directions, respectively. $J$ Jacketing, $B$ bracing and $S$ shear wall

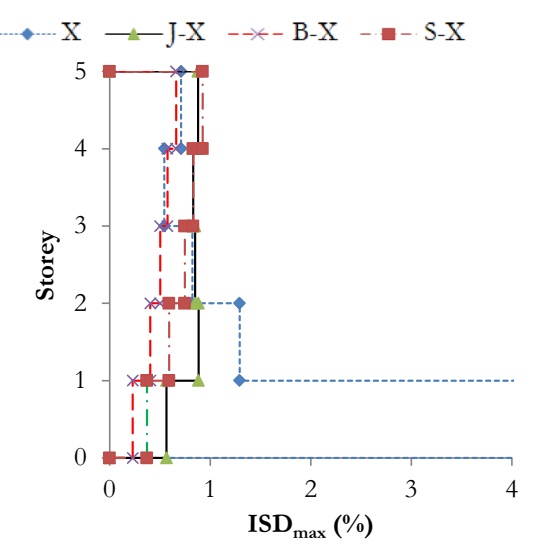

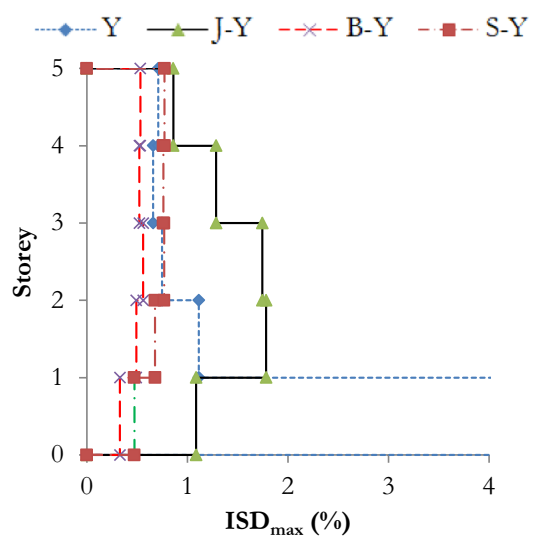

ISD $_{\max }$ by almost $2.5-5$ times in the $X$ direction and 3-7 times in the $Y$ direction relatively compared with the original CCP2 building. Figure 9 illustrates the distribution of drift profile for the MRT1 building, such that retrofit measures reduced the $\mathrm{ISD}_{\max }$ for this particular IM ranges from 4 to 10 times in the $X$ direction and 1.3-4 times in the $Y$ direction as compared with the original building. Figure 10 demonstrates the inter-storey drift distribution for the MRT2 building, and a large reduction in the inter-storey drift was recorded after retrofit interventions. It was observed that the $\mathrm{ISD}_{\max }$ could be reduced by almost 4-7 times in the $X$ direction and 3.5-7 times in the $Y$ direction relatively compared to the original MRT2 building. In case of jacketing, the recorded drift reduction was not as expected, which exhibited almost $1 \%$ and $2 \% \mathrm{ISD}_{\max }$ in the $X$ and $Y$ directions, respectively. This state of the building could be expected to have moderate to extensive damages.

Based on the above discussions, it can be concluded that the steel bracing was found to be relatively much more effective in reducing the maximum inter-storey drift and is valid for all case study buildings. Similarly, jacketing retrofit measure was observed to be less effective when compared to other retrofit methods, exhibiting higher ISD $_{\max }$.

\section{Incremental dynamic analysis (IDA) curves}

The seismic performance of the selected buildings under consideration was analysed through IDA curves, such that the $\mathrm{ISD}_{\max }$ as EDP was plotted along the abscissa and IMs along the ordinate (Vamvatsikos and Cornell 2002). The IDA curves for the CCP1, CCP2, MRT1, and MRT2 buildings are presented in Figs. 11, 12, 13, 14, 15, 16, 17, 18, respectively. The statistical distribution of demand parameters as a function of IMs for the selected ground motion records are shown by the light solid lines representing the individual IDA curve. The large dispersion of EDPs were recorded for the same IM, which signifies that the building response is primarily dependent on the selected earthquake frequency contents and recorded durations. The mean IDA curve is represented by the solid line, which is the average of EDPs obtained from 42 ground motions at each IM. Generally, the increase in IMs exhibits increase in the seismic demand as expected, but in some cases a decrease in $\mathrm{ISD}_{\max }$ was recorded even for increasing IMs. This is potentially due to hardening of the some structural elements and is most likely the non-retrofitted structural members or frames near new added elements. Such phenomena were largely observed in the existing buildings for higher IMs, and for few earthquakes in case of the retrofitted buildings. The building with and without retrofit measures showed the worst response for the Gorkha earthquake; which has a recorded duration of $130 \mathrm{~s}$ and maximum PGA of $0.164 \mathrm{~g}$.

Figure 11 presents the IDA curve for the existing CCP1 building with and without retrofit measures. The plot for the existing CCP1 building exhibits larger ISD $_{\max }$ even for lower IMs and can be expected to behave elastically until $0.2 \mathrm{~g}$ PGA and it can be predicted to have reached partial collapse and collapse states beyond $0.4 \mathrm{~g}$. These attained drift can be highly improved after the implementation of retrofit strategies, such that the elastic region can be extended until $0.4 \mathrm{~g}$ PGA with jacketing and shear wall, whereas for the subjected IMs in case of bracing element.

The vulnerability assessment of the existing CCP1 building with and without retrofit can be investigated in more a generalized form through the comparison of mean IDA curves presented in Fig. 12. The mean IDA curves for the original CCP1 building exhibited $5 \% \mathrm{ISD}_{\max }$ in both directions, at $0.5 \mathrm{~g}$ PGA, which illustrates the total collapse of the original building and it was reduced below $2 \% \mathrm{ISD}_{\max }$ in both directions using retrofit measures. It can also be observed that the steel bracing exhibits reduced ISD $_{\max }$ in both directions, whereas comparable drift in case of shear wall and jacketing. The ISD ${ }_{\max }$ for building with steel bracing exhibits lower than $0.5 \% \mathrm{ISD}_{\max }$ in both directions. All the above results and discussions led to the conclusion that the steel bracing was relatively more effective in improving seismic performance, followed by jacketing and shear wall, respectively. 




(a)

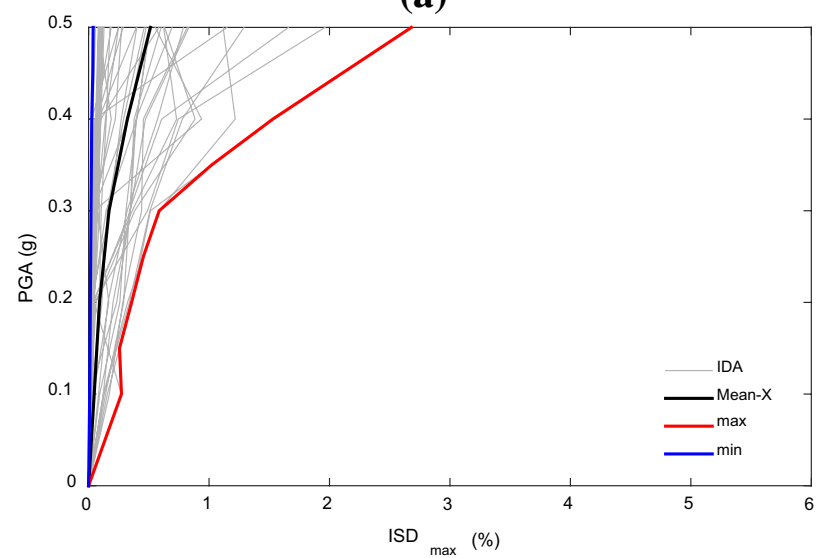

(c)

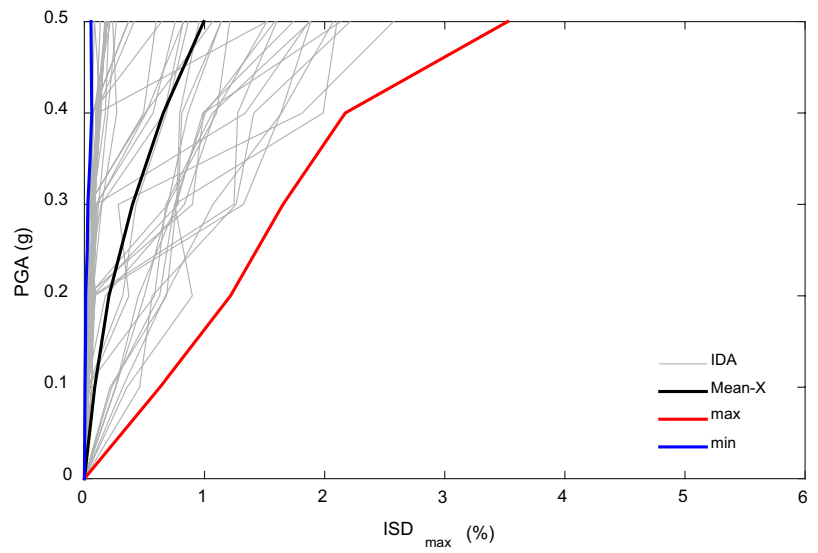

(b)

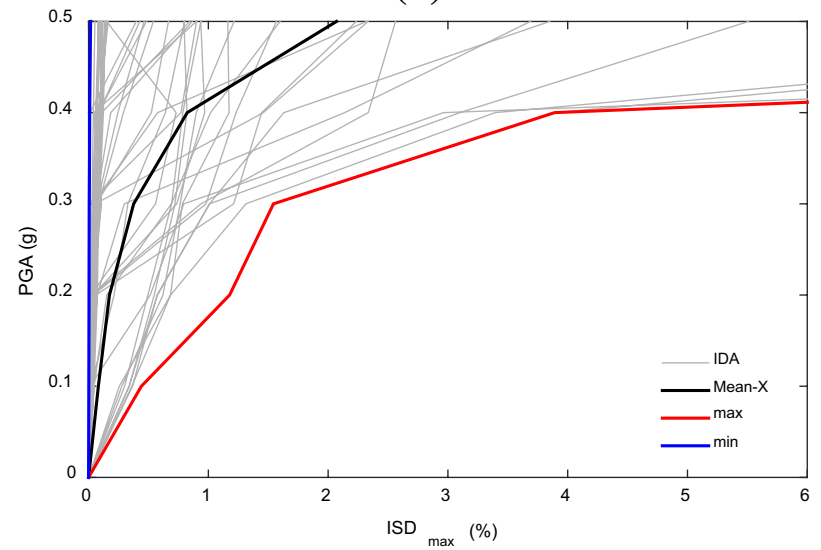

(d)

Fig. 11 IDA curves for the CCP1 building and its retrofit in $X$ direction; $\mathbf{a}$ CCP1, $\mathbf{b}$ jacketing, $\mathbf{c}$ bracing, and $\mathbf{d}$ shear wall
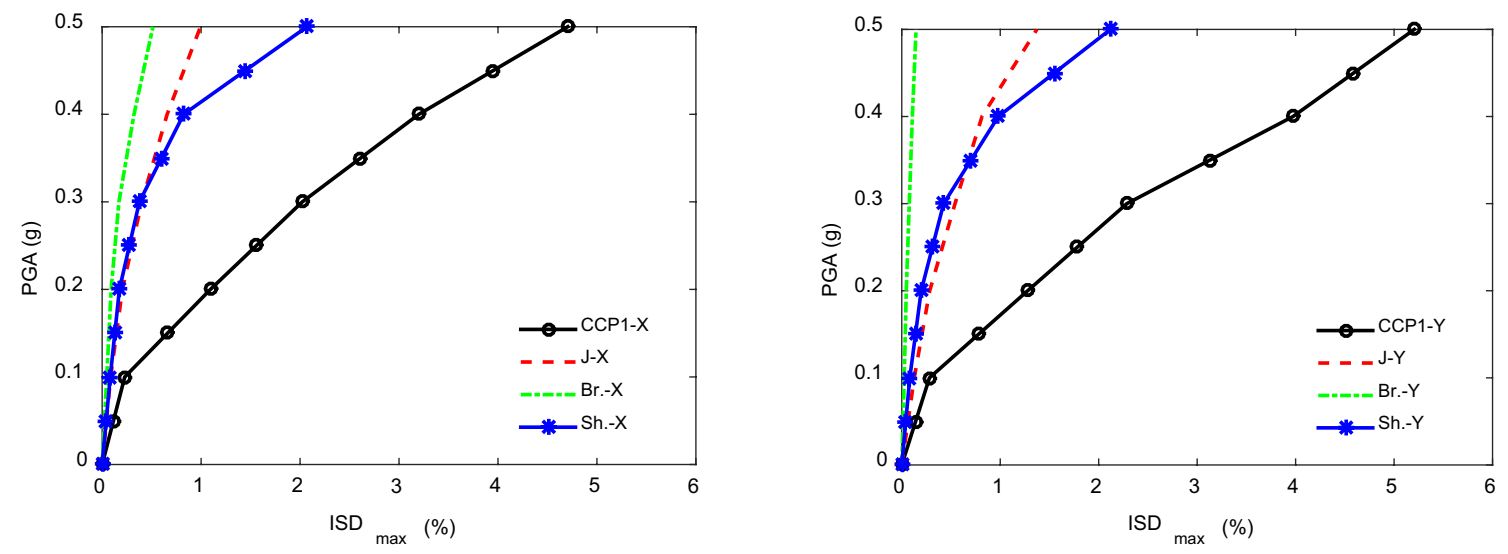

Fig. 12 Comparative mean IDA curves for the CCP1 building with and without retrofit measures in the $X$ and $Y$ directions, respectively. $J$ Jacketing, $B r$. bracing and $S h$. shear wall

The IDA curves for the existing CCP2 building with and without retrofit measures are presented in Fig. 13. The plot illustrates that the original CCP2 building can be expected to behave elastically for the majority of subjected earthquakes until $0.2 \mathrm{~g}$ PGA. In addition, the larger dispersion of EDP can be recorded for the same IM even for lower IMs, illustrating the fragile behaviour of the original building. After introducing the retrofit measures the entire retrofitted buildings behaved elastically for the subjected IMs and for the majority of selected earthquakes. 


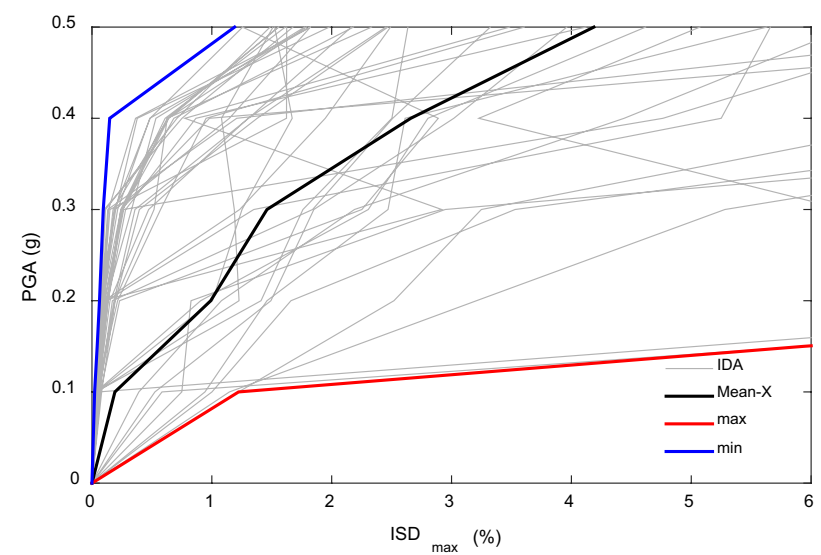

(a)

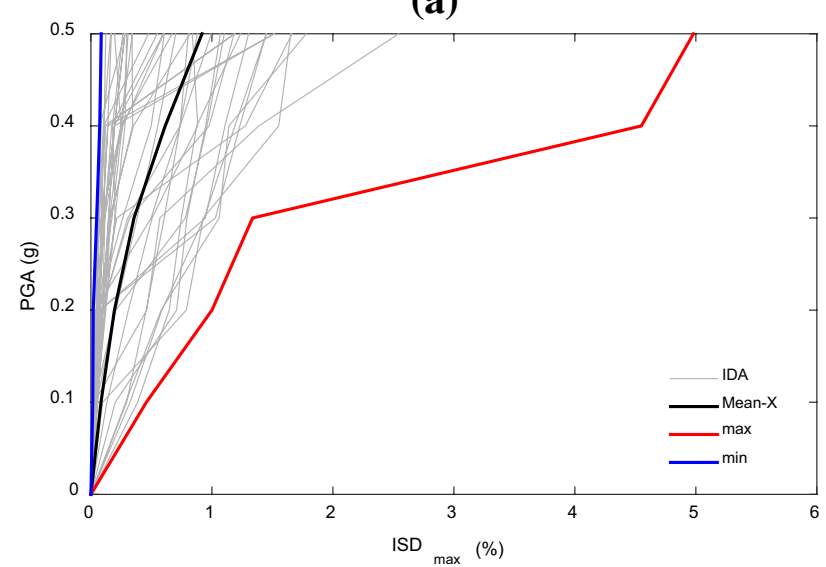

(c)

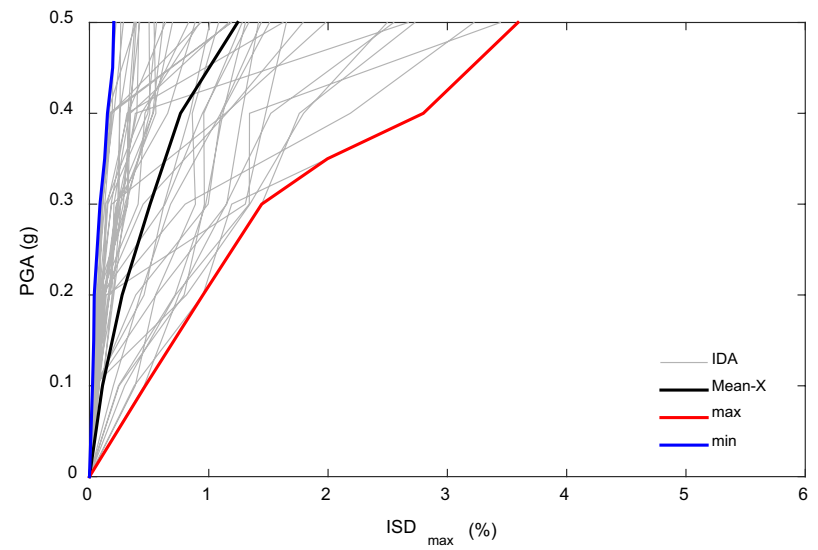

(b)

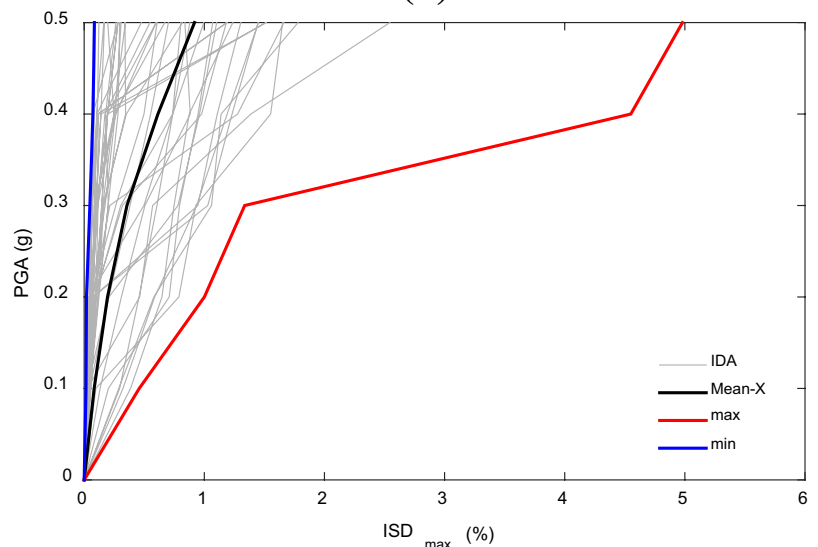

(d)

Fig. 13 IDA curves for the CCP2 building and its retrofit in the $X$ direction; a CCP2, $\mathbf{b}$ jacketing, $\mathbf{c}$ bracing, and $\mathbf{d}$ shear wall
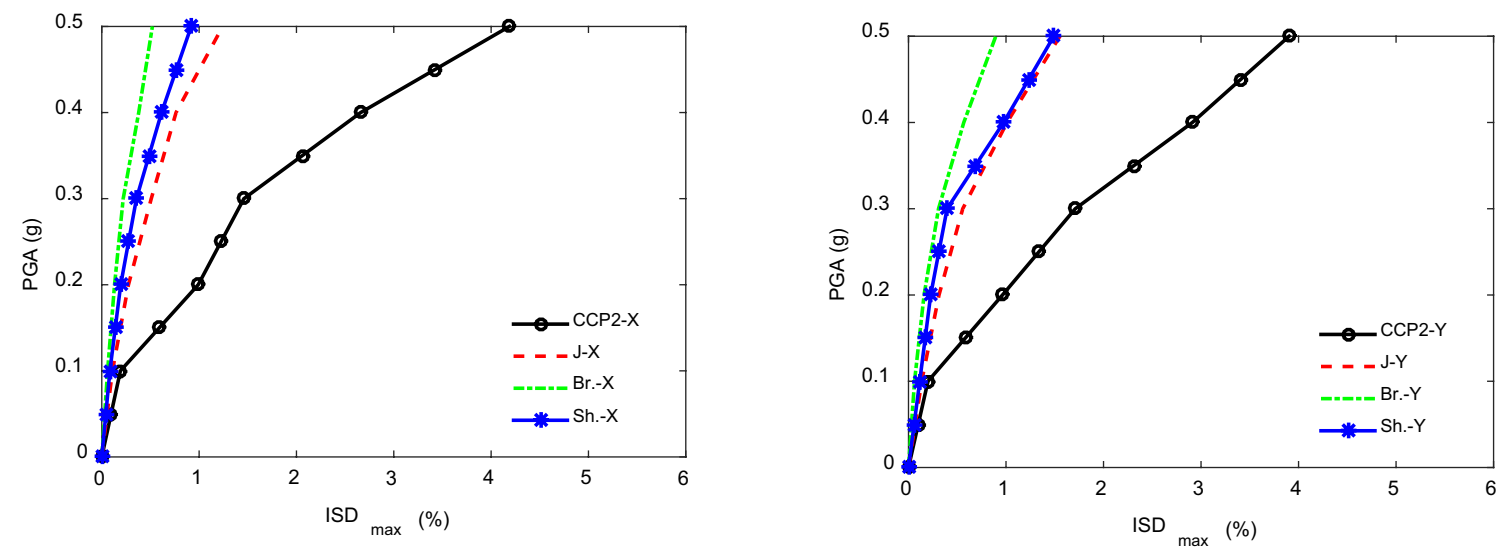

Fig. 14 Comparative mean IDA curve for the CCP2 building with and without retrofit measures in the $X$ and $Y$ directions, respectively. $J$ Jacketing, $B r$. bracing and $S h$. shear wall

Figure 14 presents the comparative mean IDA curves for the CCP2 building with and without retrofit measures, and shows that the existing CCP2 building can considerably reduce the mean drift to lower level than initially expected. The dynamic results revealed that steel bracing was found to be highly effective in reducing the $\mathrm{ISD}_{\max }$ in both directions, when compared with other retrofit measures. The retrofit measures could reduce the mean drift by almost three to four times in both directions compared to the original building, at $0.5 \mathrm{~g}$ PGA. The entire plots concluded that all retrofit 


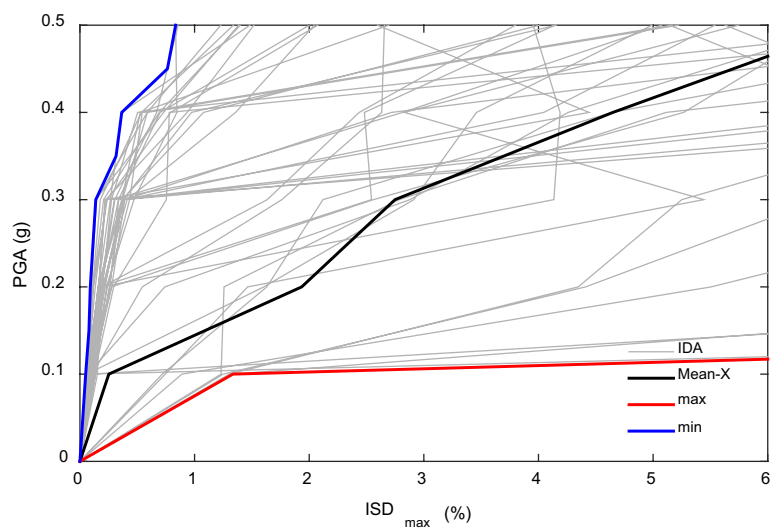

(a)

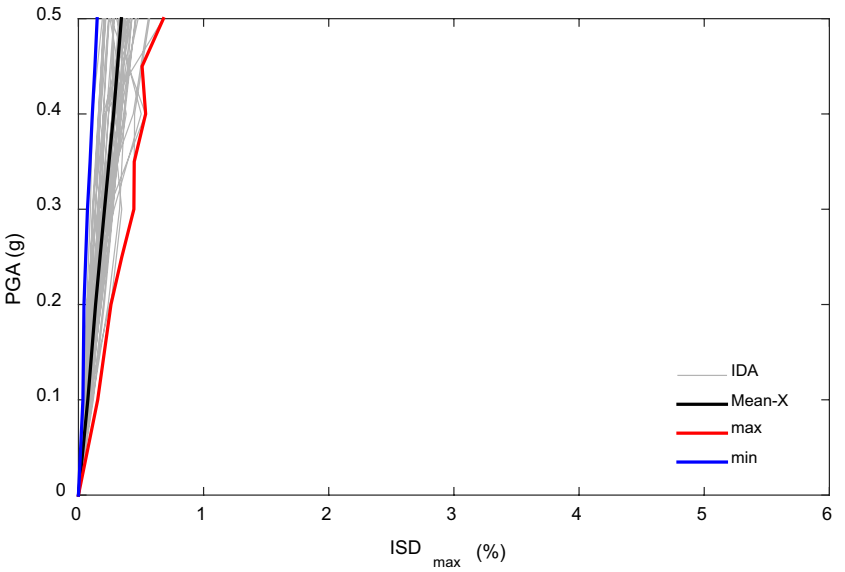

(c)

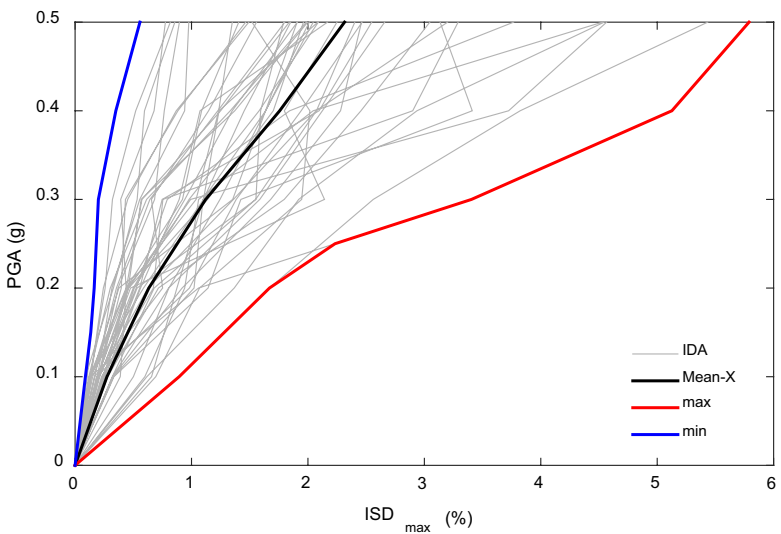

(b)

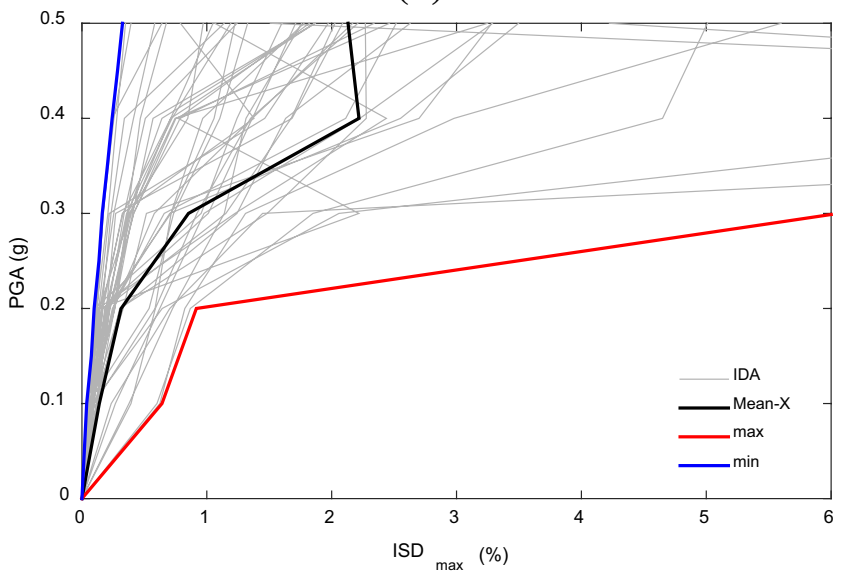

(d)

Fig. 15 IDA curves for the MRT1 building and its retrofit in $X$ direction; a MRT1, b jacketing, $\mathbf{c}$ bracing, and $\mathbf{d}$ shear wall
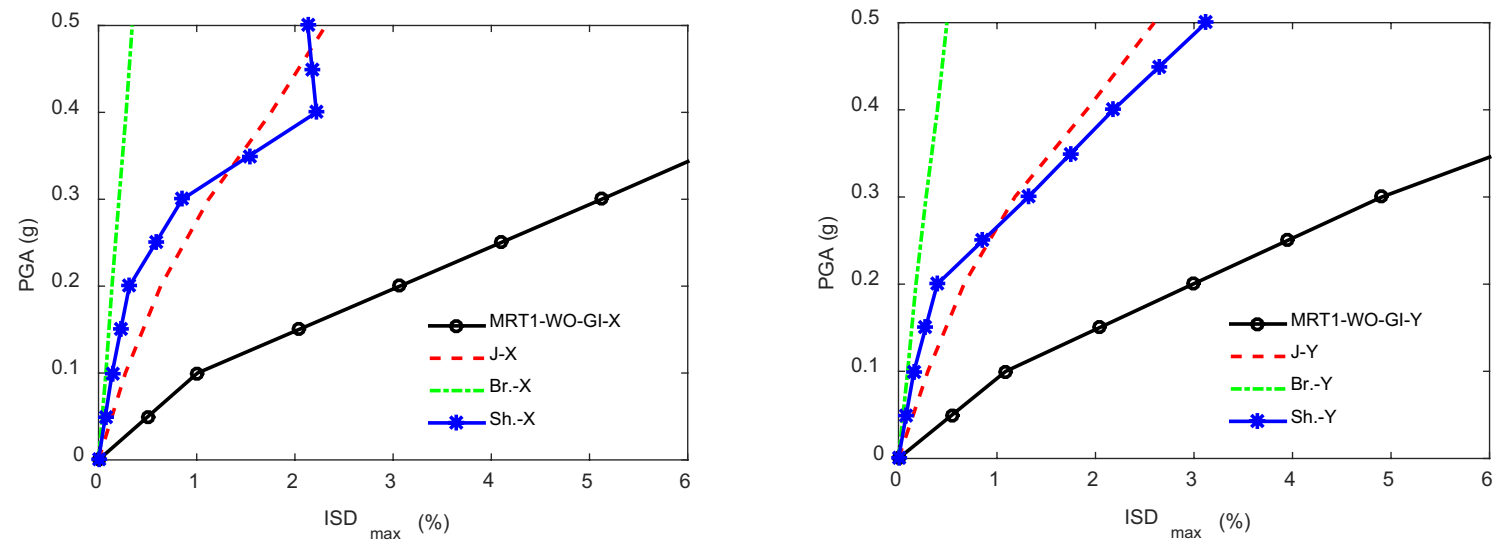

Fig. 16 Comparative mean IDA curve for the MRT1 building with and without retrofit measures in the $X$ and $Y$ directions, respectively. $J$ Jacketing, $B r$. bracing and $S h$. shear wall

techniques considered for the study would be effective in enhancing the seismic performance of the existing CCP2 building, but steel bracing was found to be more effective.

Figure 15 presents the IDA curves for the MRT1 building with and without retrofit measures, illustrating a large scattering of the EDP even for lower IMs, such that the original building was observed to have reached extensive damage state at $0.2 \mathrm{~g}$ PGA. This could be mainly due to soft-storey building consideration in the present study; as a consequence, the probability of soft-storey failure at the 


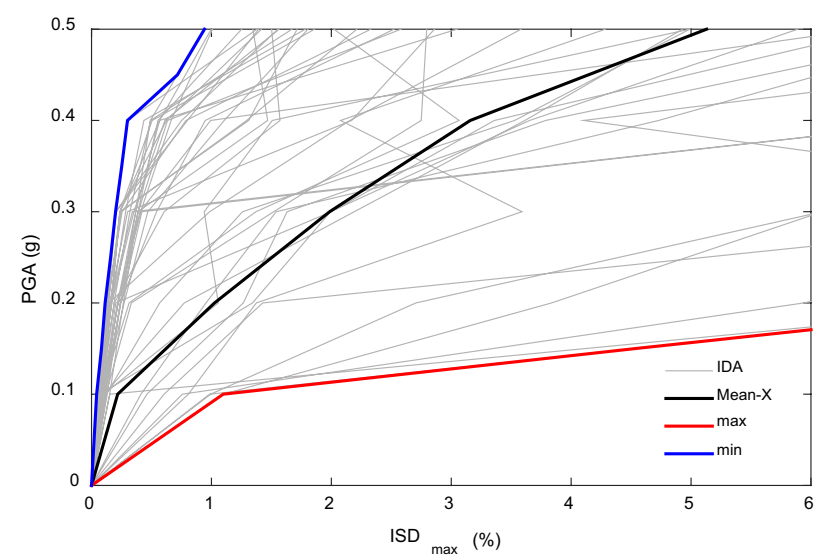

(a)

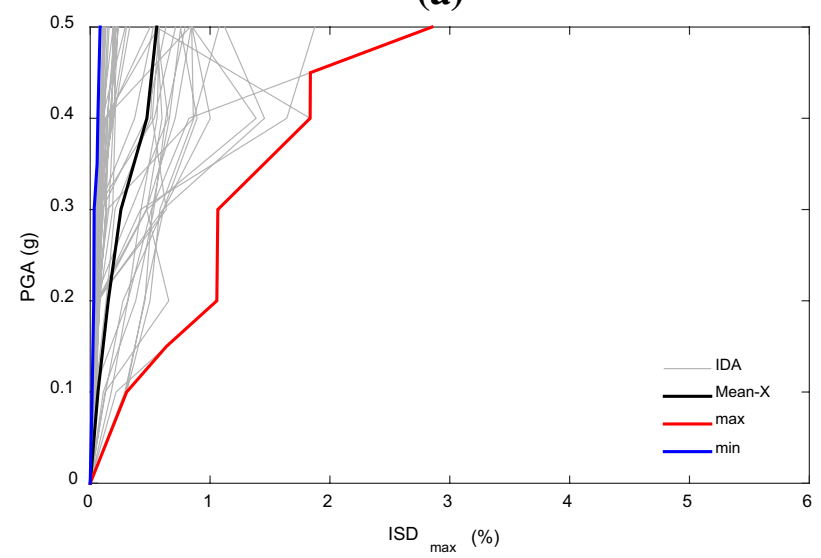

(c)

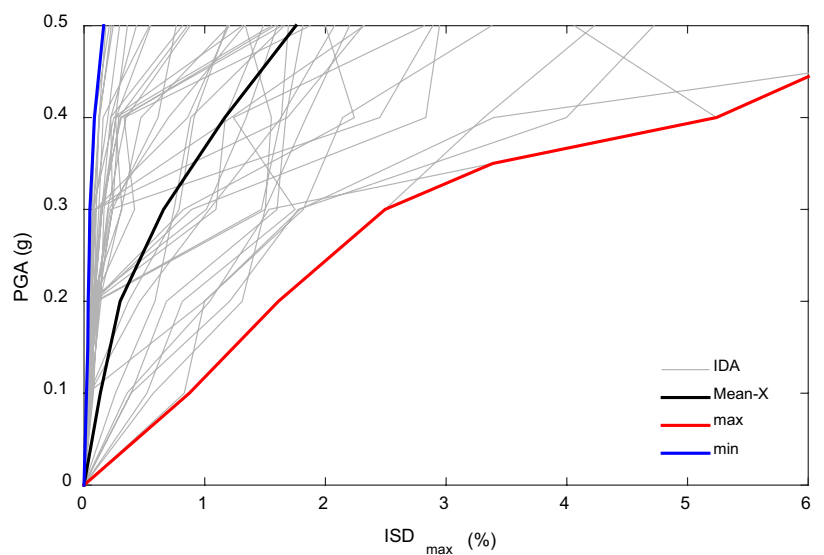

(b)

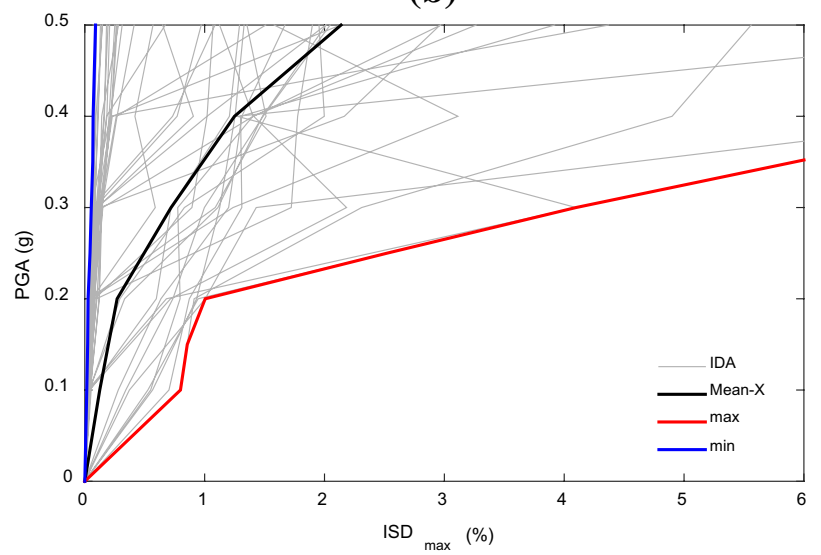

(d)

Fig. 17 IDA curves for the MRT2 building and its retrofit in the $X$ direction; a MRT2, $\mathbf{b}$ jacketing, $\mathbf{c}$ bracing, and $\mathbf{d}$ shear wall
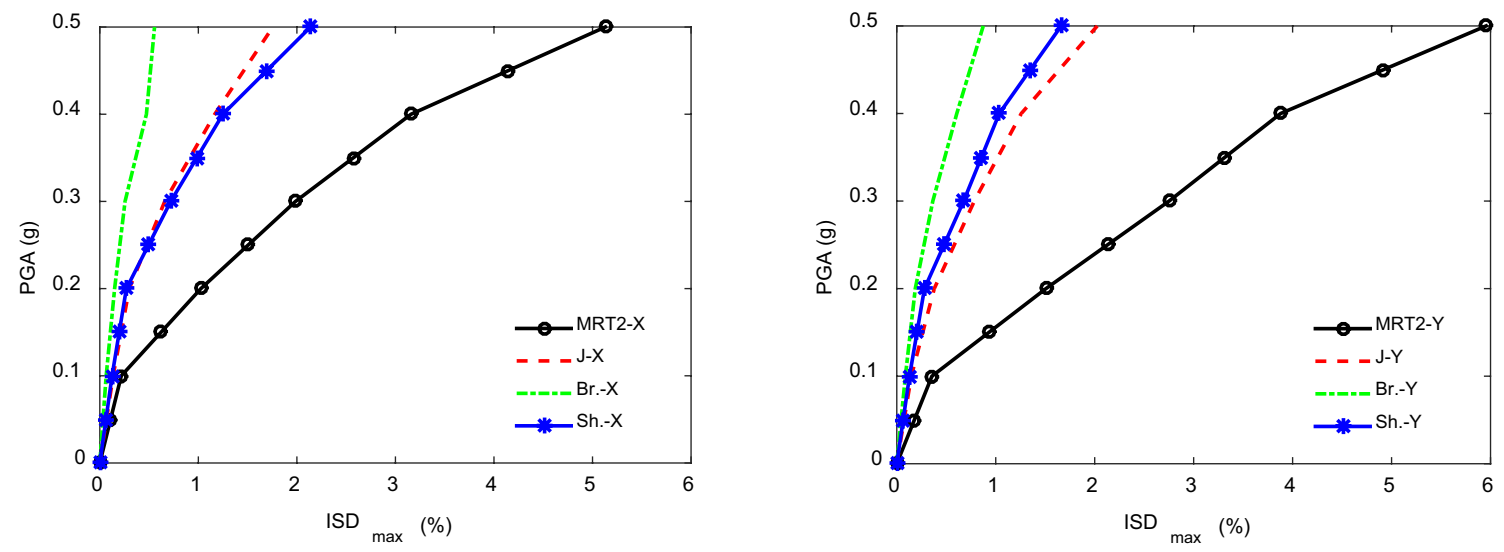

Fig. 18 Comparative mean IDA curves for the MRT2 building with and without retrofit measures in the $X$ and $Y$ directions, respectively. $J$ Jacketing, $B r$. bracing and $S h$. shear wall

ground storey is highly susceptible. The original building can be expected to behave elastically until $0.1 \mathrm{~g}$ PGA for the majority of the subjected earthquakes, whereas it can be extended to $0.2 \mathrm{~g}$ and $0.3 \mathrm{~g}$ PGA using jacketing and shear wall, respectively, and behaves elastically for the subjected IMs for steel braced building.

The above discussed IDA curves might be beneficial in providing an overview of the discrete distributions of the 
building's response with respect to IM, but it is difficult to generalize and draw a conclusion regarding the selection of the most effective retrofit measures. Figure 16 presents the comparative mean IDA curves for the MRT1 building with and without retrofit measures, and shows that all the retrofit techniques considerably reduced the mean drift to minimum values. In addition, steel braced building was found to be relatively much more effective in both directions compared to other measures. The attained mean drift, at $0.3 \mathrm{~g}$ PGA, for the MRT1 building was more than $6 \%$, which predicts the collapse of the building and such drift was reduced below $1.5 \%$ using retrofit measures. This indicates that the potential collapse of the original building can be avoided using retrofit measures leading to moderate to extensive damage states. Furthermore, the building with retrofit measures, at $0.5 \mathrm{~g}$ PGA, revealed an average drift of approximately $2.5 \%$ and $3 \%$ in the $X$ and $Y$ directions, respectively. This state of the building would potentially have extensive to partial collapse, but the life loss could be prevented or reduced due to its large deformation capability before collapse.

The IDA curves for the MRT2 building with and without retrofit are displayed in Fig. 17. It can be observed from the plot that existing MRT2 building exhibits elastic region until $0.1 \mathrm{~g}$ PGA and reaches extensive damage level beyond $0.2 \mathrm{~g}$ PGA and partial collapse and collapse states at $0.4 \mathrm{~g}$. This state of the existing building seismic performance can be enhanced by many folds with the addition of retrofit measures, such that the $\mathrm{ISD}_{\max }$ was reduced to a larger extent. After retrofit measures, the building with jacketing and shear walls can be expected to behave elastic behaviour until $0.3 \mathrm{~g}$ PGA in both directions, whereas for the subjected IMs in case of steel braced building.

Figure 18 presents the comparative mean IDA curves for the MRT2 building. All the retrofit measures were found to reduce the mean $\mathrm{ISD}_{\max }$ to minimum values. It was observed that steel braced building exhibited the lowest mean ISD ${ }_{\max }$ for the considered IMs, when compared with other measures. In addition, the MRT2 building with shear walls and jacketing was recorded to exhibit comparable mean IDA curves in the $X$ direction; whereas in the $Y$ direction shear wall measures exhibited slightly lower mean $\mathrm{ISD}_{\max }$ than the jacketed building. The original MRT2 building exhibited more than $5 \%$ mean ISD $_{\max }$, at $0.3 \mathrm{~g}$ PGA, such that it experienced total collapse. After introducing retrofit techniques, the mean $\mathrm{ISD}_{\max }$ was reduced to below $2 \%$ in both directions, where the buildings had moderate to extensive damage states. From the above discussions, it can be concluded that the steel bracing for the building was found to be much more effective than other techniques.

\section{Fragility curves}

The fragility curve is a statistical tool to estimate the level of structural damage states at certain IMs, plotted PGA along the abscissa and probability of exceeding along the ordinate. The fragility curve for a structure provides the conditional probability of exceeding a given state of damage taking into account the record of variability. The fragility curves are developed for the ISD ${ }_{\max }$ obtained from the non-linear dynamic time history analyses, such that the $\mathrm{ISD}_{\max }$ was assumed to be lognormally distributed. The present study will not discuss the development of the fragility curve; the EDP of the building, in particular IMs, was compared with the threshold drift as proposed by Rossetto and Elnashai (2003), presented in Table 3. The fragility curves for lower damage states, i.e. slight and light, were not presented, as the conditional probability of exceeding the peak for such damage states was comparatively similar for buildings with and without retrofit measures. The dotted vertical line represents the boundary of $0.3 \mathrm{~g}$ PGA, which represents an earthquake of return period 475 years.

Figure 19 presents the comparative fragility curves for the CCP1 building with and without retrofit measures for moderate to collapse states. The entire plot illustrates that the addition of retrofit measures significantly reduces the conditional probability of exceeding damage states relatively compared to the existing CCP1 building. The steel bracing was recorded to have highly improved the seismic performance of the existing building, such that the probability of damage states was lowered to minimum as compared to other techniques. For the moderate damage state, the steel braced building was found to be considerably effective in reducing the failure probability, whereas the effect of other techniques was insignificant. The probability of exceeding moderate damage state, at $0.3 \mathrm{~g}$ PGA, can be reduced by almost $50 \%$ using the steel bracing. In addition, the probability of exceeding extensive damage for the existing building, at $0.3 \mathrm{~g}$ PGA, was almost $43 \%$, and was reduced to 10 to $2 \%$ through the addition of retrofit techniques. Similarly, in case of partial collapse, the bracing retrofit revealed theoretically zero failure probability, and most interestingly, jacketing displayed better seismic performance than shear wall. The probability of exceeding partial collapse for the existing building, at $0.3 \mathrm{~g} \mathrm{PGA}$, was almost $22 \%$ and was reduced to 8 to $4 \%$ with intervention using retrofit techniques. Furthermore, the probability of exceeding collapse for buildings with steel bracing and jacketing was theoretically zero. The probability of collapse for existing CCP1 building, at $0.3 \mathrm{~g}$ PGA, was $14 \%$ and was reduced to $2 \%$ with RC shear walls. Therefore, based on the comparison fragility curve results, it can be concluded that the steel braced building illustrates superior seismic performance. 


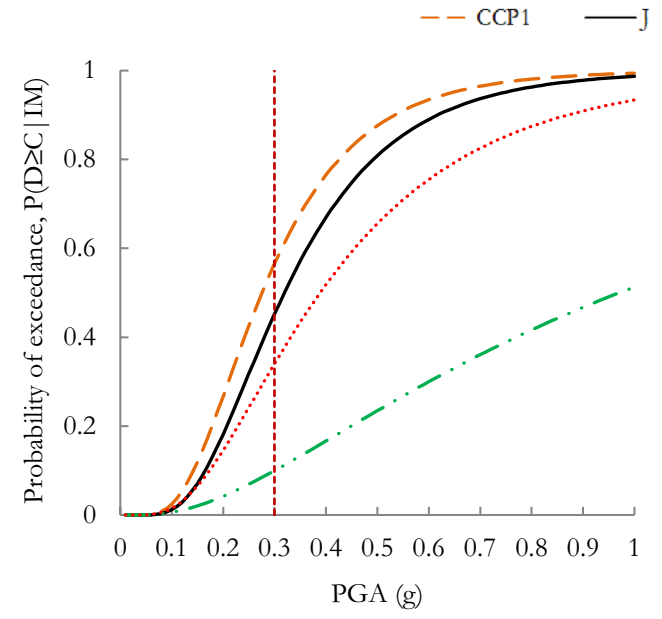

(a)

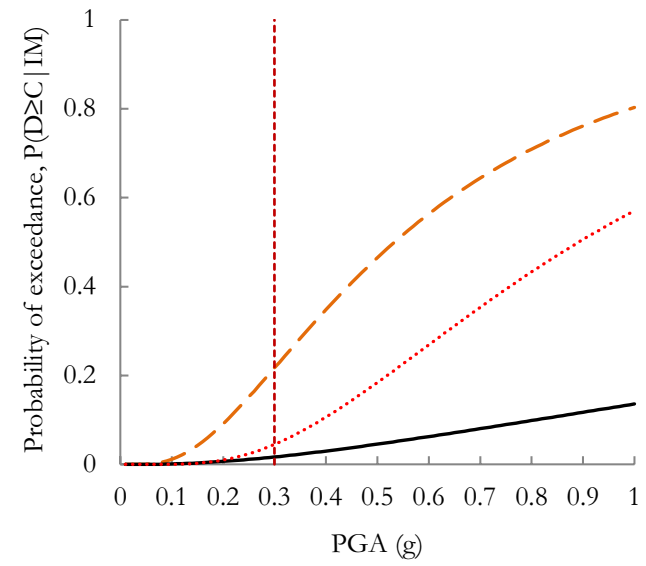

(c)

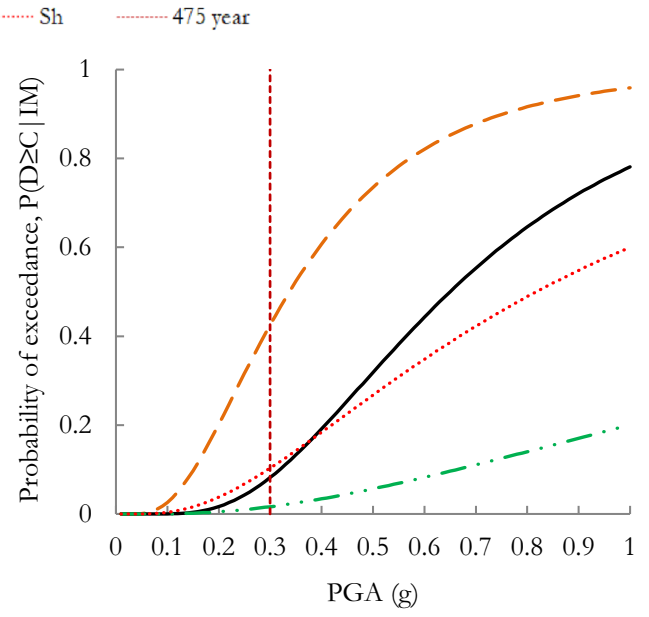

(b)

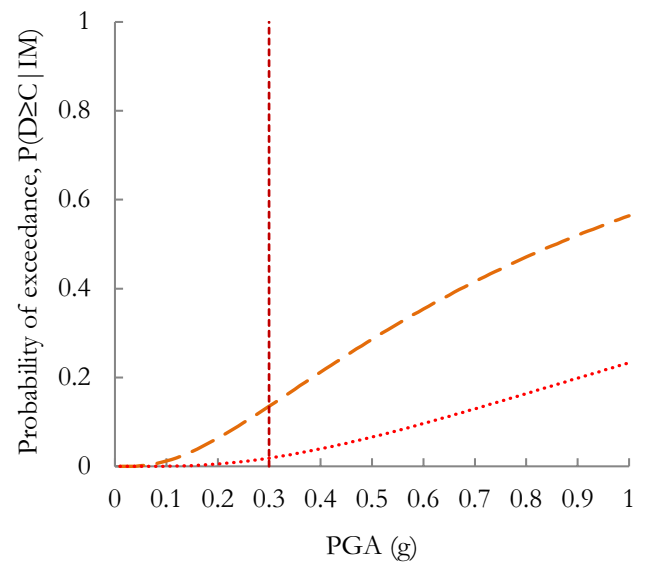

(d)

Fig. 19 Fragility curves with and without retrofit for the CCP1 building; a moderate, b extensive, c partial collapse, and d collapse. $J$ Jacketing, $B r$. bracing and $S h$. shear wall

Figure 20 presents the comparative fragility curves for the CCP2 building for moderate to collapse states, where comparison was carried out between the existing and retrofitted buildings. All of the plots illustrate that a considerable reduction in the failure probabilities was recorded after the addition of retrofit measures. In addition, it was found that the steel braced building exhibited minimal failure probability at all IMs when compared to other techniques. The retrofit measures could reduce the moderate damage probability by almost $20-70 \%$ compared to the original building, at $0.3 \mathrm{~g}$ PGA. In case of extensive damage, the failure probability was reduced to almost $(30-40) \%$, at $0.3 \mathrm{~g}$ PGA. Similarly, the comparative fragility curve for partial collapse exhibit large reductions in failure probability with retrofit techniques. Remarkably, a change in fragility pattern was recorded for partial collapse, where the jacketed revealed better seismic performance than shear wall technique. The probability of partial collapse was reduced, at $0.3 \mathrm{~g} \mathrm{PGA}$, by approximately $25 \%$. The comparative fragility curves for the collapse state show a remarkable reduced in failure probability, which reduces to theoretically zero for all retrofit techniques. The probability of exceeding collapse for the existing building, at 0.3 g PGA, corresponded to $22 \%$ and retrofitted buildings could reduce this to below $1.5 \%$. From all the above discussions, it can be stated that the addition of retrofit techniques would be more effective in reducing the higher damage states. This also indicates that retrofit techniques are effective in reinstating the existing building to its original form so that it does not require heavy repair and maintenance works after future earthquakes. This ultimately minimizes the loss due to human injuries and fatalities, and also minimizes the structural and non-structural loss, the objectives of the present study. The steel bracing was found to be much more effective in improving the seismic performance for this particular CCP2 building. 


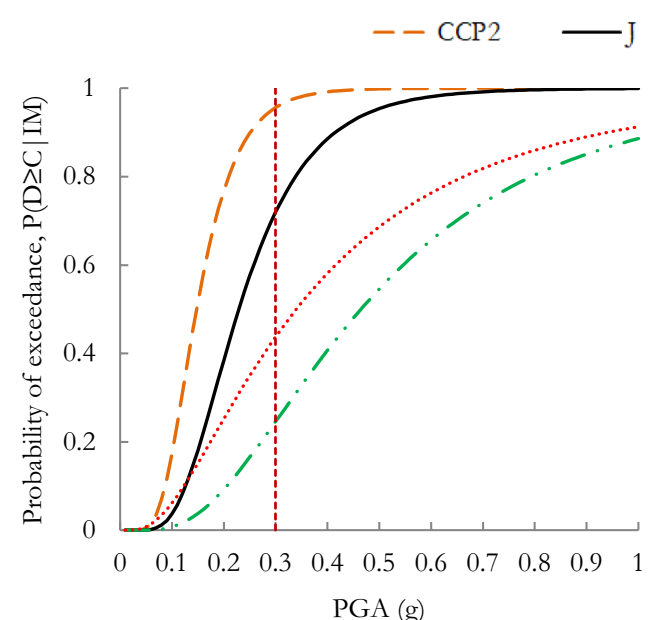

(a)

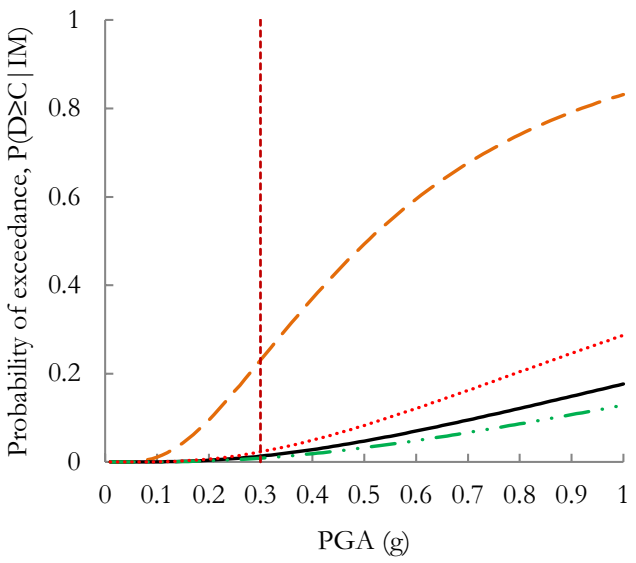

(c)

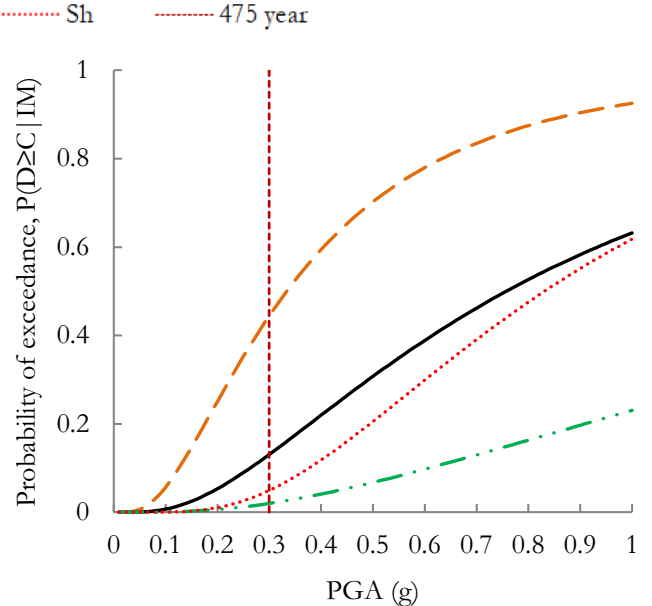

(b)

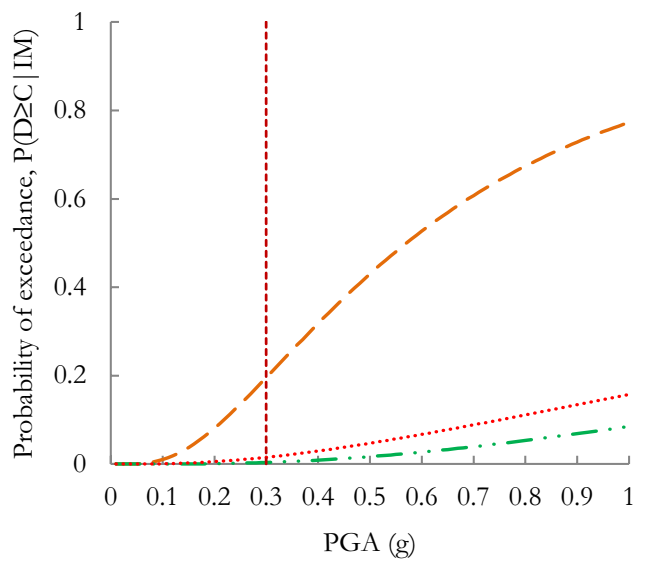

(d)

Fig. 20 Fragility curves with and without retrofit for the CCP2 building; a moderate, b extensive, $\mathbf{c}$ partial collapse, and $\mathbf{d}$ collapse. $J$ Jacketing, $B r$. bracing and $S h$. shear wall

The suitability of each retrofit technique for various damage states can be evaluated by comparing the fragility curves. Figure 21 presents the comparative fragility curve for higher damage states. All of the plots illustrated that steel braced reinforcement was the most effective in reducing the failure probabilities. The comparative fragility curves for moderate damage reveals that peak damage initially occurred below $0.1 \mathrm{~g}$ in case of the original building, and its occurrence was shifted beyond $0.5 \mathrm{~g}$ with addition of retrofit measures. Interestingly, the comparative fragility curves for steel-braced retrofitting beyond the moderate damage state revealed theoretically null failure probability. The probability of exceeding extensive damage state, at $0.3 \mathrm{~g}$ PGA, could be reduced by $60-80 \%$ using retrofit measures in the original building. In addition, the probability of exceeding partial collapse and collapse, $0.3 \mathrm{~g}$ PGA, could also be reduced by $90 \%$ and $35-40 \%$, respectively. Summarizing all the attained results, it can be concluded that the steel bracing was found to be the most effective in improving the seismic performance of existing MRT1 building, followed by concrete jacketing and RC shear wall, respectively.

The most effective and efficient retrofit techniques for the MRT2 building and the level of damage that could be reduced after their intervention can be interpreted through the comparative fragility curves, plotted between the original MRT2 building and retrofitted buildings are shown in Fig. 22. For the selected damage states, the steel braced building was observed to demonstrate lower failure probabilities. Similarly, when comparing between the buildings retrofitted with RC shear wall and concrete jacketing, shear walls were found to be slightly more effective in moderate and extensive damage states, whereas jacketing displayed better seismic performance for partial collapse and collapse states than shear wall. The failure probability of moderate damage, at $0.3 \mathrm{~g}$ PGA, could be reduced by $35-75 \%$ from the original building. Similarly, the probability of exceeding extensive damage, partial collapse and collapse, at $0.3 \mathrm{~g}$ PGA, was reduced by $25-40 \%, 25 \%$ 


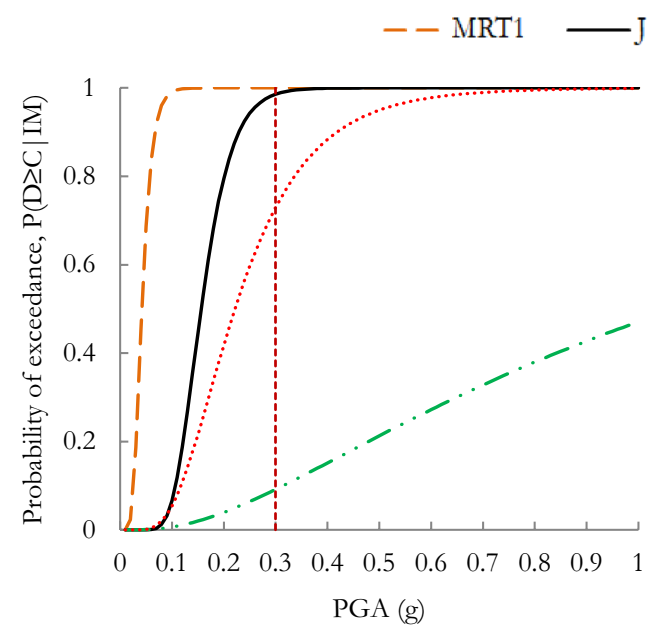

(a)

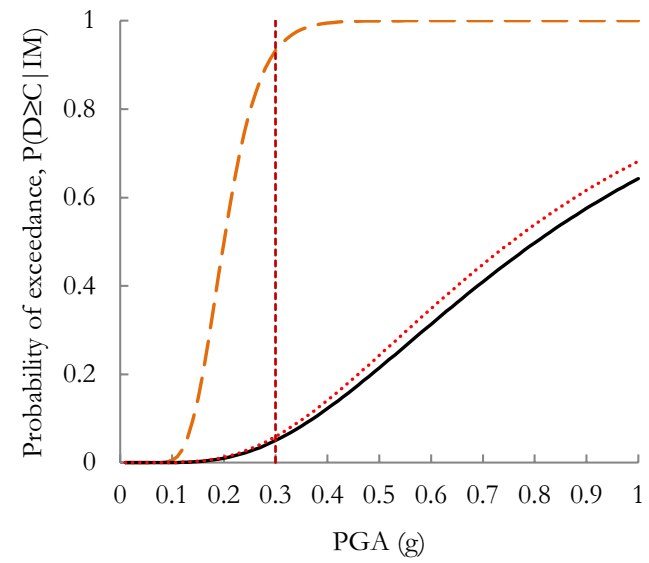

(c)

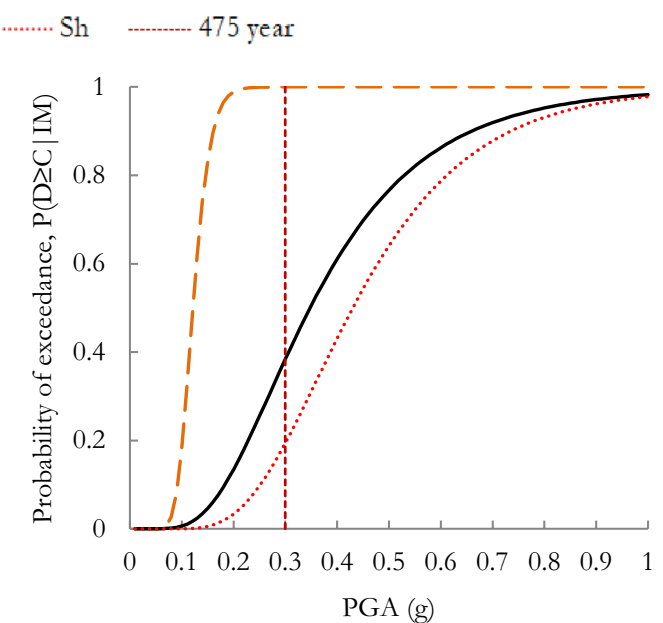

(b)

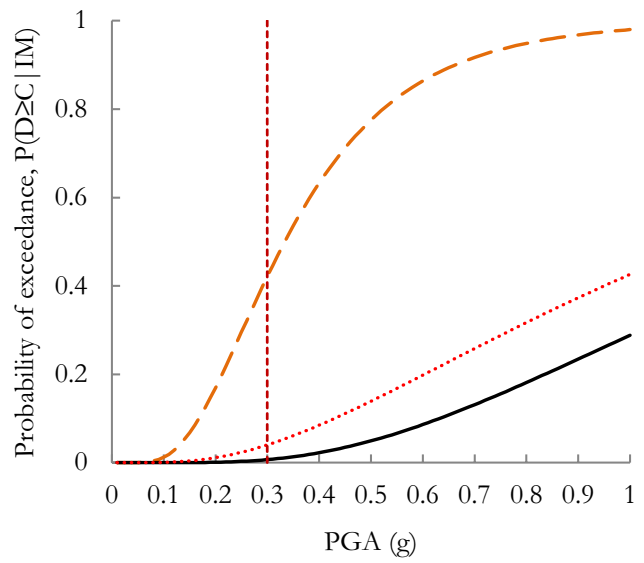

(d)

Fig. 21 Fragility curves with and without retrofit for the MRT1 building; a moderate, b extensive, c partial collapse, and d collapse. $J$ Jacketing, $B r$. bracing and $S h$. shear wall

and more than $20 \%$, respectively, compared with the original building. Theoretically, the probability of exceeding partial collapse and collapse was reduced to lower values, i.e. $<2 \%$ and $<1 \%$, respectively. Summarizing all the obtained results, it can be concluded that steel bracing was found to be relatively much more effective in enhancing seismic performance.

\section{Conclusions}

The preliminary detailed investigations concluded that the case study non-engineered and pre-engineered buildings were found to be seismic deficient and later employed three commonly practised retrofit measures with the objective that the retrofit measures could enhance seismic performance in the existing buildings. The various conclusions obtained are summarized below.
- The retrofit measure improves the global building stiffness, strength and ductility capacity of the existing buildings. The increase in stiffness for the CCP1 building ranges from 4 to 7 times and increase in maximum strength by $2-3$ times in both directions relatively compared to as-built CCP1 building. In case of the CCP2 building, the increase in stiffness was 1.5-2.5 times and maximum strength increased by $2-3.5$ times in both directions. For the MRT1 building, the increase in stiffness and maximum strength capacity were almost 3.5-7 and 4-10 times, respectively. Furthermore, in case of the MRT2 building, the increase in stiffness was $1.5-3$ times and maximum strength increased by 1.5-3 times compared to as-built building.

- All of the retrofit measures significantly reduced the maximum inter-storey drift to lower level. A single storey drift concentration recorded in the existing buildings can be evenly distributed throughout the building. 


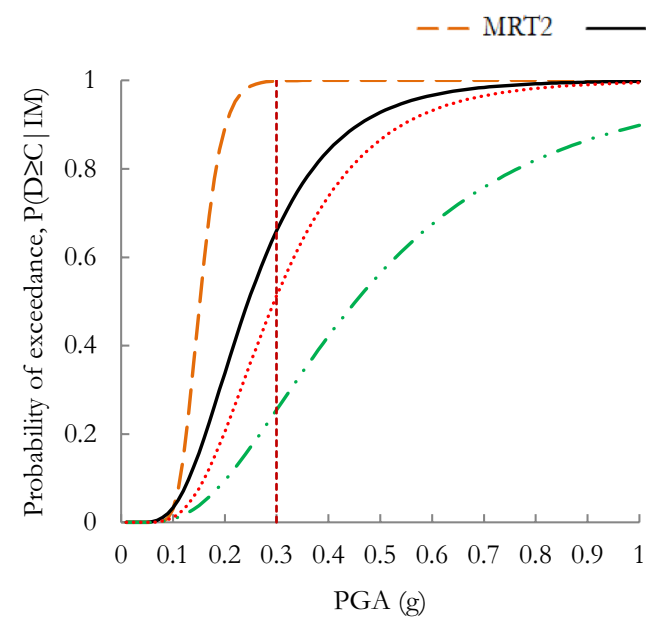

(a)

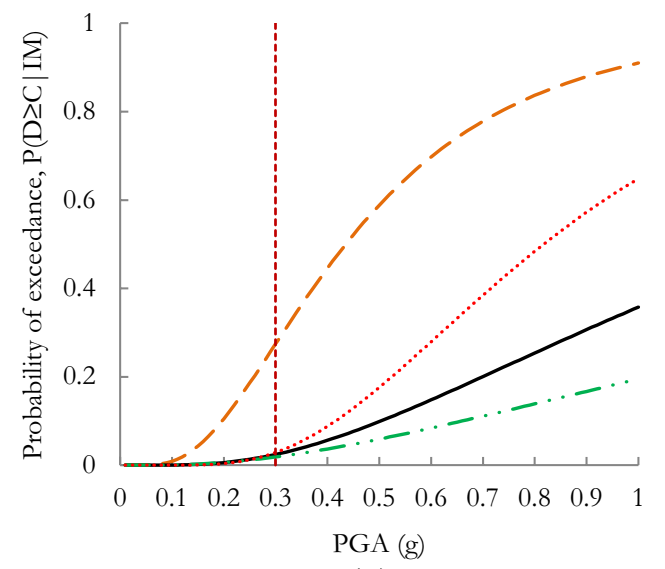

(c)



(b)

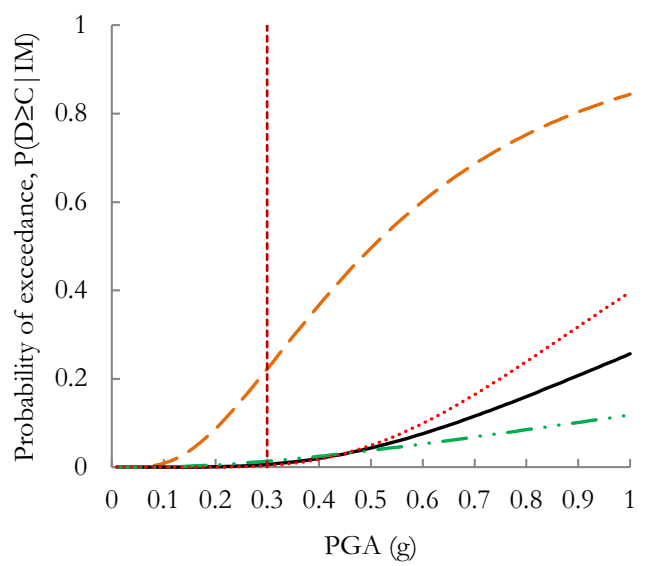

(d)

Fig. 22 Fragility curves with and without retrofit for the MRT2 building; a moderate, b extensive, c partial-collapse, and d collapse. $J$ Jacketing, $B r$. bracing and $S h$. shear wall

This ensures the uniform distribution of stiffness and strength throughout the height.

- The intervention of steel bracing found to be more effective in reducing the inter-storey drift to lower values compared to other techniques. The maximum inter-storey drift was reduced by almost 5-10 times in $X$ and 2-4 times in $Y$ direction of the CCP1 building. In case of the CCP2 building, the $\mathrm{ISD}_{\max }$ was reduced by $2.5-7$ times in both directions. The $\mathrm{ISD}_{\max }$ was reduced by $4-10$ times in the $X$ direction and 1.3-4 times in the $Y$ direction of the MRT1 building. Furthermore, the ISD $\mathrm{Imax}_{\text {was }}$ reduced by almost 4-7 times in both directions for the MRT2 building.

- The IDA curve illustrates that with the increase in IMs, the building exhibits increasing seismic response, as expected. The original CCP1 building was expected to be in the elastic region until $0.1 \mathrm{~g}$, but the retrofit introduction can increase it up to $0.3 \mathrm{~g}$ PGA. The mean IDA curves concluded that the steel bracing exhibited lower
$\mathrm{ISD}_{\max }$ as compared to other techniques. The original building in the collapsed state, at $0.5 \mathrm{~g}$ PGA, could be reinstated to moderate to extensive damage states by the addition of retrofit measures in the CCP1 building. In case of the CCP 2 building, the retrofit measures reduced the mean drift ranges from three to four times in both directions compared to the original CCP2 building. The mean drift for the MRT1 building, at $0.3 \mathrm{~g}$ PGA, was above $5 \%$ and could be reduced to below $1.5 \%$ using retrofit measures. The recorded mean drift of more than 5\% for the MRT2 building, at $0.3 \mathrm{~g}$ PGA, could be reduced to below $2 \%$ in both directions using the retrofit measures.

- The retrofit measures largely reduced the building failure probabilities, such that the original CCP1 buildings failure probability in case of extensive damage, at $0.3 \mathrm{~g}$ PGA, was $43 \%$ and could be reduced from 10 to $2 \%$. The probability of exceeding partial collapse and collapse states could be reduced below $8 \%$ and $2 \%$, respectively. For the CCP2 building, the probability of exceeding par- 
tial collapse and collapse states, at $0.3 \mathrm{~g}$ PGA, could be reduced below $2 \%$ and $1.5 \%$, respectively. The probability of partial collapse and collapse states, at $0.3 \mathrm{~g}$ PGA, for the MRT1 building reduced by almost $90 \%$ and $40 \%$ respectively. Furthermore, the probability of partial collapse and collapse states, at $0.3 \mathrm{~g}$ PGA, for the MRT2 building could be reduced by more than $25 \%$ and $20 \%$ respectively.

\begin{abstract}
Acknowledgements This work has been developed under the collaborative initiative "Holistic Approach to Sustainability of Existing and New Structures", supported by the College of Civil Engineering of Fuzhou University, China, and the Fuzhou-Roma Tre Universities SinoItalian Centre. The first author would like to acknowledge the financial support of SmartLink PhD Grant, under Erasmus Mundus Action 2, reference SL15DF0066. This work was also financially supported by: Project POCI-01-0145-FEDER-007457, CONSTRUCT, Institute of R\&D In Structures and Construction funded by FEDER funds through COMPETE2020, Programa Operacional Competitividade e Internacionalização and by national funds through FCT, Fundação para a Ciência e a Tecnologia. This work was object of specific financial support of FCT through the P0CI-01-0145-FEDER-016898- "ASPASSI Safety Evaluation and Retrofitting of Infill masonry enclosure Walls for Seismic demands".
\end{abstract}

Open Access This article is distributed under the terms of the Creative Commons Attribution 4.0 International License (http://creativeco mmons.org/licenses/by/4.0/), which permits unrestricted use, distribution, and reproduction in any medium, provided you give appropriate credit to the original author(s) and the source, provide a link to the Creative Commons license, and indicate if changes were made.

\section{References}

Alcocer SM (1993) RC frame connections rehabilitated by jacketing. J Struct Eng 119:1413-1431

Altin S, Anil Ö, Kara ME (2008) Strengthening of RC nonductile frames with RC infills: An experimental study. Cement Concr Compos 30:612-621

Antoniou S, Pinho R (2004) Development and verification of a displacement-based adaptive pushover procedure. J Earthq Eng 8:643-661

Asteris PG, Chrysostomou CZ, Giannopoulos IP, Smyrou E (2011) Masonry infilled reinforced concrete frames with openings. In: COMPDYN 2011 III ECCOMAS Thematic Conference on computational methods in structural dynamics and earthquake engineering

Barkhordari M, Dayhim N, Nicknam A, Razi M, Mehdizad S (2013) Numerical modeling of reinforced concrete columns strengthened with composite materials. Asian J Civ Eng (BHRC) 14(4):557-576

Bauschinger J (1887) Variations in the elastic limit of iron and steel. J Iron Steel Inst 12:442-444

Bertero V, Brokken S (1983) Infills in seismic resistant building. J Struct Eng 109:1337-1361

Bush TD, Talton CR, Jirsa JO (1990) Behavior of a structure strengthened using reinforced concrete piers. Struct J 87:557-563

Chaulagain H, Rodrigues H, Spacone E, Varum H (2015) Assessment of seismic strengthening solutions for existing low-rise RC buildings in Nepal. Earthq Struct 8(3):511-539
Chrysostomou CZ, Poljansek M, Kyriakides N, Taucer F, Molina FJ (2013) Pseudo-dynamic tests on a full-scale four-storey reinforced concrete frame seismically retrofitted with reinforced concrete infilling. Struct Eng Int 23:159-166

Crisafulli FJ (1997) Seismic behaviour of reinforced concrete structures with masonry infills

Delgado P, Rodrigues V, Rocha P, Santos M, Arêde A, Pouca NV et al (2005) Seismic retrofitting of structural elements. An experimental characterization. In: 250th Anniversary of the 1755 Lisbon Earthquake

Dumaru R, Rodrigues H, Furtado A, Varum H (2016) Seismic vulnerability and parametric study on a bare frame building in Nepal. Front Built Env 2:31

El-Amoury T, Ghobarah A (2005) Retrofit of RC frames using FRP jacketing or steel bracing. J Seismol Earthq Eng 7:83

Eurocode 8 (2005) Design of structures for earthquake resistance-Part 1: general rules, seismic actions and rules for buildings. Brussels: European Committee for Standardization

FEMA-273 (1997) NEHRP guidelines for the seismic rehabilitation of buildings. Report No. FEMA 273. Federal Emergency Management Agency, Washington DC, USA

Filippou F, Fenves G (2004) Methods of analysis for earthquake-resistant structures, vol 6, pp 6.1-6.65

Fiorato AE, Sozen MA, Gamble WL (1970) An investigation of the interaction of reinforced concrete frames with masonry filler walls, The department5 of defense office of the secretary of the army office of civil defense. http://hdl.handle.net/2142/14303

Furtado A, Rodrigues H, Varum H, Costa A (2014) Assessment and strengthening strategies of existing RC buildings with potential soft-storey response. In: 9th international masonry conference (IMC), Portugal

Furtado A, Rodrigues H, Arêde A, Varum H (2015) Influence of the in plane and out-of-plane masonry infill walls' interaction in the structural response of RC buildings. Procedia Eng 114:722-729

Gao X, Balendra T, Koh C (2013) Buckling strength of slender circular tubular steel braces strengthened by CFRP. Eng Struct 46:547-556

Ghobarah A (2004) On drift limits associated with different damage levels. In: Performance-based seismic design concepts and implementation: proceedings of the international workshop, vol 28. Bled, Slovenia

Goel S, Lee H (1990) Seismic strengthening of RC structures by ductile steel bracing system. In: Proc. 4th US NCEE

IS 13920:1993 (2003) Ductile detailing of reinforced concrete structures subjected to seismic forces-code of practice. Bureau of Indian Standards, ManakBhavan, 9 Bahadur Shah ZafarMarg, New Delhi

IS 15988:2013 (2013) Preliminary seismic evaluation aid for reinforced concrete framed structures. Bureau of Indian Standards, ManakBhavan, 9 Bahadur Shah ZafarMarg, New Delhi

IS 1893 (Part1):2002 (2002) Indian Standard Criteria for Earthquake Resistant Design Structures (fifth Revision). Bureau of Indian Standards, ManakBhavan, 9 Bahadur Shah ZafarMarg, New Delhi

IS 456:2000 (2000) Plain and reinforced concrete code of practice. Bureau of Indian Standards. Fourth Revision

IS 800:2007 (2007) General construction in steel-code of practice. Bureau of Indian Standards. Third Revision

Júlio E, Branco F, Silva V (2003) Structural rehabilitation of columns with reinforced concrete jacketing. Progr Struct Eng Mater 5:29-37

Kaplan H, Yilmaz S, Cetinkaya N, Atimtay E (2011) Seismic strengthening of RC structures with exterior shear walls. Sadhana 36:17-34

Khoshnoudian F, Poursha M (2004) Responses of three dimensional buildings under bi-directional and unidirectional seismic excitations. In: Proceedings of the 13th World Conference on Earthquake Engineering, pp 1-6 
Liel B (2008) Assessing the collapse risk of California's existing reinforced concrete frame structures: metrics for seismic safety decisions: Stanford University

Liel AB, Haselton CB, Deierlein GG (2010) Seismic collapse safety of reinforced concrete buildings. II: comparative assessment of nonductile and ductile moment frames. J Struct Eng 137:492-502

Lopez OA, Chopra AK, Hernandez JJ (2000) Critical response of structures to multicomponent earthquake excitation. Earthq Eng Struct Dyn 29:1759-1778

Macedo L, Araújo M, Castro J (2013) Assessment and calibration of the Harmony Search algorithm for earthquake record selection. In: Proceedings of the Vienna congress on recent advances in earthquake engineering and structural dynamics

Madas P, Elnashai A (1992) A new passive confinement model for the analysis of concrete structures subjected to cyclic and transient dynamic loading. Earthq Eng Struct Dyn 21:409-431

Mander JB, Priestley MJ, Park R (1988) Theoretical stress-strain model for confined concrete. J Struct Eng 114:1804-1826

Mander JB, Nair B, Wojtkowski K, Ma J (1993) An experimental study on the seismic performance of brick-infilled steel frames with and without retrofit. In: Technical Report, ed: National Center for Earthquake Engineering Research (NCEER)

Martinez-Rueda JE, Elnashai A (1997) Confined concrete model under cyclic load. Mater Struct 30:139-147

Mehrabi AB, Benson Shing P, Schuller MP, Noland JL (1996) Experimental evaluation of masonry-infilled RC frames. J Struct Eng 122:228-237

Menegotto M, Pinto P (1973) Method of analysis for cyclically loaded rc frames including changes in geometry and non-elastic behaviour of elements under combined normal force and bending. In: IABSE Congress Reports of the Working Commission

Holmes M (1961) Steel frames with brickwork and concrete infilling. Proc Inst Civ Eng 19:473-478

NBC 205:1994 (1994) Mandatory Rules of Thumb, Reinforced Concrete Buildings without Masonry Infill. HMG/Ministry of Housing and Physical Planning, Department of Building, Kathmandu, Nepal

NBC 000:1994 (1994) Requirements for state-of-the art design an introduction, D. o. Building, ed. Kathmandu, Nepal

Pinho R, Elnashai A (2000) Dynamic collapse testing of a full-scale four storey RC frame. ISET J Earthq Technol 37:143-163

Ram TD, wang G (2013) Probabilistic seismic hazard analysis in Nepal. Earthq Eng Eng Vibr 12:577-586

Ricci P, De Risi MT, Verderame GM, Manfredi G (2016) Procedures for calibration of linear models for damage limitation in design of masonry-infilled RC frames. Earthq Eng Struct Dyn 45:1315-1335

Rodrigues HFP (2012) Biaxial seismic behaviour of reinforced concrete columns. Universidade de Aveiro (Portugal)

Rossetto T, Elnashai A (2003) Derivation of vulnerability functions for European-type RC structures based on observational data. Eng Struct 25:1241-1263
Sattar S (2013) Influence of masonry infill walls and other building characteristics on seismic collapse of concrete frame buildings, University of Colorado at Boulder

Savoia M, Buratti N, Ferracuti B, Martin P, Palazzo G (2010) Considerations about non linear static analysis of a reinforced concrete frame retrofitted with FRP. Mech Computational 29:10173-10182

SEAOC (1995) Vision 2000, performance based seismic engineering of buildings, vols. I and II: conceptual framework. Sacramento (CA): Structural Engineers Association of California

Seismosoft (2004) SeismoStruct-a computer program for static and dynamic nonlinear analysis of framed structures [online]

Sharma K, Deng L, Noguez CC (2016) Field investigation on the performance of building structures during the April 25, 2015, Gorkha earthquake in Nepal. Eng Struct 121:61-74

Shokrzadeh A, Miri M (2012) Study on nonlinear static analysis of R/C frames retrofitted with steel plate shear wall, 15 World conference on earthquake engineering, Lisbon

Shrestha S (2014) Probabilistic seismic hazard analysis of Kathmandu city, Nepal. Int J Eng Res Gener Sci 2:24-33

Smyrou E, Blandon C, Antoniou S, Pinho R, Crisafulli F (2011) Implementation and verification of a masonry panel model for nonlinear dynamic analysis of infilled RC frames. Bull Earthq Eng 9:1519

Subedi B, Parajuli HR (2016) Probabilistic seismic hazard analysis of Nepal. In: Proceedings of IOE Graduate Conference, pp 265-270

Taghavi S, Miranda E (2003) Response assessment of nonstructural building elements: Pacific Earthquake Engineering Research Center

Tasnimi A, Masoomi A (1999) Evaluation of response of reinforced concrete frames strengthened with steel bracing. In: Proceedings of the third international conference on seismology and earthquake engineering

Vamvatsikos D, Cornell CA (2002) Incremental dynamic analysis. Earthq Eng Struct Dyn 31:491-514

Varum H (2003) Seismic assessment, strengthening and repair of existing buildings, $\mathrm{PhD}$, Universidade de Aveiro, University of Aveiro

Varum H, Furtado A, Rodrigues H, Dias-Oliveira J, Vila-Pouca N, Arêde A (2017) Seismic performance of the infill masonry walls and ambient vibration tests after the Ghorka 2015, Nepal earthquake. Bull Earthq Eng 15:1185-1212

Varum H, Dumaru R, Furtado A, Barbosa AR, Gautam D, Rodrigues $H$ (2018) Seismic performance of buildings in Nepal after the Gorkha earthquake Impacts and Insights of the Gorkha Earthquake. Elsevier, Amsterdam, pp 47-63

Youssef M, Ghaffarzadeh H, Nehdi M (2007) Seismic performance of RC frames with concentric internal steel bracing. Eng Struct 29:1561-1568

Publisher's Note Springer Nature remains neutral with regard to jurisdictional claims in published maps and institutional affiliations. 